\title{
Effect of entrained air voids on the microstructure and mass transport properties of concrete
}

\author{
H.S. Wong ${ }^{\mathrm{a}^{*}}$, A.M. Pappas ${ }^{\mathrm{a}}$, R.W. Zimmerman ${ }^{\mathrm{b}}$ and N.R. Buenfeld ${ }^{\mathrm{a}}$ \\ ${ }^{a}$ Concrete Durability Group, Department of Civil and Environmental Engineering, Imperial College London \\ ${ }^{b}$ Department of Earth Science and Engineering, Imperial College London
}

\begin{abstract}
The effects of entrained air on microstructure and transport properties of concrete with up to $11.5 \%$ air at different w/c ratios, curing and conditioning regimes were investigated. It was found that air voids disrupt the packing of cement and increase the heterogeneity of the microstructure. The width of the affected interface is around $30 \mu \mathrm{m}$. Gaseous diffusivity and permeability are increased by up to a factor of 2-3 at the highest air contents. This effect is similar to that due to increasing w/c ratio from 0.35 to 0.50 when samples are conditioned at $52 \%$ r.h or $50^{\circ} \mathrm{C}$. The effect on sorptivity is less consistent, while the effect on electrical conductivity is influenced by the moisture condition of the air voids. It is estimated that every $1 \%$ increase in air concrete increases transport by $10 \%$ or decreases it by $4 \%$, depending on whether the air voids act as conductors or insulators.
\end{abstract}

Keywords: Porosity (B); Interfacial transition zone (B); Diffusion (C); Permeability (C); Transport properties (C);

\section{Introduction}

A typical concrete contains around 1-2\% vol. of air voids that are inadvertently entrapped because of incomplete compaction. Air voids may also be deliberately incorporated by means of a suitable surfactant, i.e. an air entraining admixture. It is well established that air entrainment enhances the resistance of concrete to damage by repeated exposure to freeze-thaw cycles and salt scaling, by providing a system of discrete, small and closely spaced spherical voids that are well dispersed throughout the cement paste. The size of the entrained air voids is generally between ten and hundreds of microns. To ensure adequate frost protection, the spacing of the air voids should be smaller than a critical distance, typically 200-250 $\mu \mathrm{m}$ [1,2]. However, for simplicity and convenience, most standards prescribe the total air content by assuming that the spacing factor is inversely proportional to air content. For example, the recommended air content according to ACI 201.2R-01 [3] ranges from 3-7.5\% depending on the maximum aggregate size and severity of the exposure, with a tolerance of $\pm 1.5 \%$ allowed for field concretes. The volume and size of the entrained air voids depend on many factors, including the type and amount of air-entraining agent, materials and mix composition, mixing and placing techniques. These issues and concepts relating to freeze-thaw damage and the beneficial effects of air entrainment have been reviewed elsewhere [2-5].

\footnotetext{
${ }^{*}$ Corresponding author: Tel: +44 (0)20 7594 5956; Fax: +44 (0)20 72252716

E-mail address: hong.wong@imperial.ac.uk
} 
Because concrete contains around 65-75\% aggregate and all of the air voids reside in the cement paste, a small amount of air entrainment causes a significant change to the microstructure of the paste, and to its pore structure in particular. This in turn may have a significant effect on the properties of the hardened concrete. A well known example is strength loss that accompanies air entrainment. As a general rule of thumb, one-percentage increase in air content results in about 5\% decrease in the compressive strength of concretes at equal water-to-cement (w/c) ratios. However, a more significant reduction in strength has been reported particularly when the air avoids cluster at the aggregate-paste interface [6, 7]. Air entrainment also increases workability, improves consistency and reduces the bleeding and segregation tendency of fresh concrete $[2,5]$.

Whereas there is an extensive body of work on characterising the air void system and determining its requirements for frost protection, very little research has been carried out on understanding the effects of entrained air on other aspects of hardened concrete such as mass transport processes and resistance to other forms of deterioration. Air voids are penetrable, but because they appear isolated in the microstructure and do not form a continuous flow channel, they are often assumed to make little or no contribution to the bulk transport properties of concrete. Thus, air voids are treated as inert inclusions similar to aggregate particles. Air voids may disturb the packing of cement grains and the distribution of porosity, but this effect could be negligible due to their small size relative to aggregates. Some studies suggest that air entrainment decreases the permeability of concrete, but this is often a result of a lower w/c ratio in the air-entrained mixes to take advantage of its improved workability [2, 8]. Increasing the air content is accompanied by a change in other variables, such as the cement and aggregate content, that may have a larger influence on transport. For example, increasing the air content decreases the aggregate content if the cement content and effective w/c ratio are held constant, As such, it may be difficult to isolate the actual contribution of the entrained air voids.

The air voids may be empty or water-filled, depending on the exposure history of the concrete, and this has a significant influence on measured transport properties. For example, in McCarter et al. [9], the electrical resistivity of OPC concretes with 1:2:4 mix proportions, w/c ratio 0.8 and entrained air up to $16 \%$ was continuously monitored with wet curing from 24 hrs up to 80 days. It was found that electrical resistivity increased significantly with air content and the study concluded that air voids behave as non-conducting particles in a way similar to aggregates. However, in another study, Toutanji [10] measured the AASHTO T277 rapid chloride permeability (RCP) of concrete containing 2-15\% entrained air and $0-20 \%$ silica fume at w/c ratio 0.41 . Samples were cured at $100 \%$ r.h. and $22^{\circ} \mathrm{C}$ for 7 days then dried at $30 \%$ r.h. and $28^{\circ} \mathrm{C}$ up to the age of 35 days. The results show that air entrainment increases the RCP values significantly and because the RCP is a measure of electrical conductivity, this finding would seem to contradict that of McCarter et al. [9]. A probable explanation for the inconsistency is that the samples in Toutanji [10] were vacuum saturated prior to testing as per AASHTO T277 recommendations [11], and thus the air voids were water-filled and able to participate in electrical conduction.

The aim of this study is to carry out a systematic investigation into the influence of entrained air voids on the microstructure and bulk transport properties of concrete under saturated and non-saturated conditions. Several transport mechanisms are examined, because the influence of entrained air on each may not be the same. Understanding how the microstructure influences mass transport properties is vital for the development of more durable materials and accurate service-life prediction models. In order to model mass transport properties, it is necessary to identify the phases where 
flow predominates. Also, mass transport tests are increasingly being used as performance and durability indicators, thus it is essential to understand how air entrainment can influence test results.

\section{Experimental}

\subsection{Materials and mix proportions}

Fourteen concrete mixes were prepared according to the mix proportions shown in Table 1. The main mix variables were the free water-to-cement mass ratio (w/c: 0.50 \& 0.35) and air content. The cement was a Portland cement CEM 1 42.5N that complies with EN197-1:2000. Tap water was used as batch water. The aggregates were Thames Valley gravel $(5-12.7 \mathrm{~mm})$ and sand $(<5 \mathrm{~mm})$ that complies with the BS 882 medium grading. The fine-to-total aggregate mass ratio was 0.40 . The 24 -hr water absorption of the combined aggregate was $1.5 \%$. Because the aggregate was pre-dried, the amount of water needed to bring it to saturated surface-dry condition was determined and added to the batch water.

A proprietary lignosulphonate based air-entraining agent (AEA) was used to vary the amount of entrained air. The batch water was also corrected for additional water brought in by the air-entraining agent. Several trial mixes were carried out to estimate the AEA dosage to achieve low (L), medium (M) and high (H) air contents, defined arbitrarily as 3\%, 6\% and 9\%, respectively. The air content was measured on freshly mixed concrete using the ASTM C 231 pressure method. Ideally, other mix parameters should be kept constant while the air content is varied, but this is not strictly possible. To increase air content at constant w/c, either the aggregate content or the cement content has to be decreased. Most mixes were designed to have a constant aggregate volume fraction of $67 \%$. Several mixes were designed with less aggregate so that these had the same aggregate-to-cement mass ratio (a/c) or cement content as the control. These mixes are designated with * and ${ }^{+}$respectively.

\subsection{Sample preparation, curing and conditioning}

Four cylindrical samples with dimensions $100 \varnothing \times 250 \mathrm{~mm}$ were prepared for each mix. Materials were batched by mass and mixed with a pan mixer. The samples were compacted in three layers using a vibrating table with adjustable intensity and duration. Each layer was compacted until no significant amount of air bubbles escaped the top surface. The compacted cylinders were then covered with plastic sheets and wet hessian until an age of 24 hours, when they were demoulded. Several curing and conditioning regimes were applied in order to produce samples with a range of maturity, pore characteristics and degree of saturation. Two of the four cylinders from each mix were sealed in cling film and polythene bags, and left to cure at $20^{\circ} \mathrm{C}$ for 7 days. The remaining cylinders were cured in a fog room at $95-$ 99\% r.h. for 365 days. 


\begin{tabular}{|c|c|c|c|c|c|c|c|c|}
\hline Mix & $\begin{array}{l}\text { Water } \\
\left(\mathrm{kg} / \mathrm{m}^{3}\right)\end{array}$ & $\begin{array}{l}\text { Cement } \\
\left(\mathrm{kg} / \mathrm{m}^{3}\right)\end{array}$ & $\begin{array}{l}\text { Free } \\
\text { w/c }\end{array}$ & $\begin{array}{l}\text { Paste } \\
\text { (\% vol) }\end{array}$ & $\begin{array}{l}\text { Total aggregate } \\
\text { kg/m } / \mathbf{m}^{3} \text { (\% vol) }\end{array}$ & $\mathbf{a} / \mathbf{c}$ & $\begin{array}{c}\text { AEA } \\
\text { (wt. \% } \\
\text { cement) }\end{array}$ & $\begin{array}{c}\text { Air content } \\
\text { (\% vol) }\end{array}$ \\
\hline С 0.5 & 194 & 388 & 0.5 & 33 & $1721(67)$ & 4.44 & 0 & - \\
\hline C $0.5 \mathrm{~L}$ & 183 & 367 & 0.5 & 30 & $1721(67)$ & 4.69 & 0.2 & 3 \\
\hline C $0.5 \mathrm{M}$ & 165 & 330 & 0.5 & 27 & $1721(67)$ & 5.21 & 0.4 & 6 \\
\hline C $0.5 \mathrm{H}$ & 147 & 294 & 0.5 & 24 & $1721(67)$ & 5.86 & 1.0 & 9 \\
\hline C $0.5 \mathrm{H}^{*}$ & 179 & 357 & 0.5 & 29.2 & 1588 (61.8) & 4.44 & 1.0 & 9 \\
\hline $\mathrm{C} 0.5 \mathrm{H}^{+}$ & 194 & 388 & 0.5 & 31.7 & 1523 (59.3) & 3.93 & 1.0 & 9 \\
\hline C 0.35 & 161 & 460 & 0.35 & 33 & $1721(67)$ & 3.74 & 0 & - \\
\hline C $0.35 \mathrm{~L}$ & 157 & 449 & 0.35 & 30 & $1721(67)$ & 3.83 & 0.2 & 3 \\
\hline $\mathrm{C} 0.35 \mathrm{~L}^{+}$ & 161 & 460 & 0.35 & 30.7 & 1703 (66.3) & 3.70 & 0.2 & 3 \\
\hline C $0.35 \mathrm{M}$ & 142 & 405 & 0.35 & 27 & $1721(67)$ & 4.26 & 0.4 & 6 \\
\hline $\mathrm{C} 0.35 \mathrm{M}^{+}$ & 161 & 460 & 0.35 & 30.7 & $1626(63.3)$ & 3.54 & 0.4 & 6 \\
\hline C $0.35 \mathrm{H}$ & 126 & 360 & 0.35 & 24 & $1721(67)$ & 4.79 & 0.8 & 9 \\
\hline C $0.35 \mathrm{H}^{*}$ & 150 & 428 & 0.35 & 28.6 & 1603 (62.4) & 3.74 & 0.8 & 9 \\
\hline C $0.35 \mathrm{H}^{+}$ & 161 & 460 & 0.35 & 30.7 & 1549 (60.3) & 3.37 & 0.8 & 9 \\
\hline
\end{tabular}

After the designated curing period, cylinders were sectioned from the centre to produce three 50 mm thick discs for transport testing and three $8 \mathrm{~mm}$ thick discs for point count analysis and electron microscopy. Tests were carried out on the bulk material through a cut face to eliminate possible gradient effects in the cast surface. The end discs, approximately $20 \mathrm{~mm}$ thick, were discarded. Sectioning was carried out using a diamond abrasive cutter designed for brittle composite materials operated at a slow feed rate of $0.3 \mathrm{~mm} / \mathrm{s}$. Tap water was used as cooling agent. The discs were subsequently towelled dry and conditioned at $20^{\circ} \mathrm{C}$ in incubators containing soda lime to absorb $\mathrm{CO}_{2}$, and a motorised fan to generate air circulation. The 7-day old discs were conditioned at 52\% r.h, while the 1-year old discs were conditioned at $75 \%$ r.h. Saturated salt solutions of $\mathrm{Na}_{2} \mathrm{Cr}_{2} \mathrm{O}_{7}$ and $\mathrm{NaCl}$ were used to maintain the conditioning humidity at 52\% and 75\% respectively. The humidity in the conditioning boxes was constantly monitored and the salt solutions were replaced when necessary. The samples were dried for about 5-6 months until equilibrium, taken as when the rate of mass loss was no more than $0.01 \%$ /day. None of the samples showed any signs of carbonation from checks using phenolphthalein spray or in the SEM images.

\subsection{Point count analysis}

The air void structure was analysed using a modified point count procedure. Nine polished blocks of dimensions 50× $25 \times 8 \mathrm{~mm}$ were prepared per mix, i.e. three blocks from each $8 \mathrm{~mm}$-thick disc extracted from the top, centre and bottom of the cylinder. The blocks were first dried at 52\% r.h. until constant weight was achieved, and vacuum impregnated with a low viscosity epoxy containing fluorescein dye. The vacuum impregnated sample was pressurised at 2.5 bar above atmosphere for 30 min ensure a deep epoxy penetration [12]. The blocks were then ground and polished with silicon carbide and diamond abrasives in successive stages to a $1 / 4$ micron surface finish. The hardened epoxy protects 
the air void boundaries from crumbling during grinding and polishing, while the fluorescein dye enhances the contrast of the air voids. The polished blocks were examined at $100 \times$ magnification using a petrographic microscope. The fluorescence set up consists of a 100W high-pressure mercury lamp, a 450-480 nm excitation filter and a $515 \mathrm{~nm}$ barrier filter. This set up allows air voids as small as $10 \mu \mathrm{m}$ diameter to be clearly distinguishable; however, no provision was made to differentiate between entrapped air voids and entrained air voids.

The block was placed on the stage of a linear traverse device and examined by scanning along a series of parallel traverse lines that covered the whole surface. Stops were made at every $2 \mathrm{~mm}$ along the traverse line. The number of stops where the eyepiece crosshair coincides with air voids, cement paste, and aggregates, and the number of air voids intersected by the traverse line were registered with a tally counter. The total number of stops and traversed length were also noted, these were typically greater than 1500 and $3000 \mathrm{~mm}$ respectively, per mix. The total test area was at least $11000 \mathrm{~mm}^{2}$ per mix. The obtained data were then used to calculate the air content, void frequency, paste-to-air ratio, specific surface, spacing factor and aggregate content according to ASTM C457-98 [13].

\section{$2.4 \quad$ Backscattered electron imaging}

The polished blocks were examined with a field-emission scanning electron microscope in the backscattered electron (BSE) mode to assess the influence of entrained air voids on the microstructure, in particularly near the interface between air voids and cement paste. The spatial distribution of porosity and unreacted cement from air voids were measured using Euclidean Distance Mapping [14]. Thirty BSE images were obtained per sample at 350× magnification and $0.134 \mu \mathrm{m} /$ pixel spacing. The field of view of each image was $343 \times 274 \mu \mathrm{m}$. To minimise the impact of local variations, the sampling procedure should obtain many images at different locations, randomly dispersed over a large area. Because aggregates would also influence phase distribution, the imaged areas were selected such that they were located at least $50 \mu \mathrm{m}$ away from the nearest aggregate particle to avoid sampling the aggregate-paste 'interfacial transition zone'. The smallest detectable aggregate particle was about $20 \mu \mathrm{m}$ in diameter. The microscope was operated at $10 \mathrm{keV}$ beam energy and $10 \mathrm{~mm}$ working distance. The brightness and contrast settings were calibrated so that the brightness histogram of the recorded image spans the entire dynamic range of the available grey scale. The same setting was applied to all images to ensure consistency. Segmentation of the pores was carried out using the 'overflow' method [15], whereby the inflection point of the cumulative brightness histogram was taken as the upper threshold value for pores. Segmentation of the unreacted cement phase was carried out by selecting the grey value corresponding to the minimum between the peaks for hydration products and unreacted cement as the lower threshold value. The distance measured on a random section overestimates the true normal distance from phase boundaries. In this study, all distances are reported as measured and no attempt was made to correct for this effect [16]

\section{$2.5 \quad$ Transport properties}

Transport tests following the sequence of oxygen diffusion, oxygen permeation, water absorption and electrical conduction were carried out on each of three replicate $50 \mathrm{~mm}$ thick discs. Several transport mechanisms were examined, since the influence of entrained air voids on each may not be the same. These tests were chosen because of their relevance to corrosion of steel reinforcement in concrete. The testing sequence is also advantageous because the same disc can be used throughout since successive test results are not affected by the previous test [17]. In addition, oxygen 
does not react with the sample, and gaseous permeation is quicker and requires a lower pressure gradient compared to liquid permeation and hence is potentially less damaging. The sorptivity test completes in several hours, thus the effect of further hydration on the pore structure can be assumed negligible. It must be pointed out however that these tests require sample pre-drying, which may have damaging effects. Nevertheless, the drying regime that we have imposed on the samples is not considered extreme if compared to that experienced by concrete structures in some parts of the world.

Oxygen diffusivity was determined by exposing the opposite faces of the disc to a stream of oxygen and nitrogen at equal pressure. The gasses counter-diffuse through the disc and the oxygen concentration in the outflow stream was measured using a zirconia analyser to calculate diffusivity. Oxygen permeability was determined from the steady-state flow rate at $0.5,1.5$ and 2.5 bars above atmospheric pressure. The apparent permeability coefficient was calculated following Darcy's equation at each pressure, from which the intrinsic permeability was determined by applying Klinkenberg's correction. The water absorption test was performed by monitoring the mass gain due to capillary absorption with time, until saturation. Deionised water was used as the test fluid. The sorptivity coefficient was obtained from the slope of the regression line of absorbed water per unit inflow area against square-root of time. The coefficients of regression of the least-squares fit in the Klinkenberg method and water absorption plot were always greater than 0.99. A detailed explanation of the test procedures is available in [18].

The electrical conduction test was carried out at the end of the water sorptivity test by clamping the flat surfaces of the disc with two brass plates connected to a LCR databridge. A generous amount of a salt-free electrode gel was applied to ensure good electrical contact between the sample and electrodes. The resistance was then measured at an alternating current of $1 \mathrm{kHz}$ frequency to minimise polarisation effects. The resistance typically stabilises within one minute of connection. Three measurements were taken per disc and averaged. Electrical conductivity was then calculated from the measured resistance, together with the discs dimensions. For the 1-year old discs, additional measurements were made on replicates at the end of the conditioning regime (75\% r.h.) and after saturation with deionised water under vacuum, to study the effect of moisture content.

For the 1-year cured discs, diffusivity, permeability and sorptivity were measured in two cycles; the first as described above and the second following oven-drying. At the end of the electrical conduction test in the first cycle, the discs were oven dried at $50^{\circ} \mathrm{C}$ until constant mass, which took several weeks. The discs were then cooled to $20^{\circ} \mathrm{C}$ in a vacuum desiccator to avoid any moisture uptake and tested again following the same sequence. Sample porosity was estimated from the mass difference between the oven dried condition and saturated-surface dry condition.

\section{Results}

\subsection{Point count analysis}

Results from point count analysis are presented in Table 2. The measured air contents range from $0.5 \%$ to $11.5 \%$, and in most cases, the discrepancy between measured and mix design value was no more than 1\%. For mixes containing the same AEA dosage (\% by weight of cement), higher cement content tends to decrease the amount of entrained air. As expected, increasing air content increases void frequency and decreases the spacing factor. The void spacing factor for 
all mixes containing entrained air is in the range of 0.07 to $0.16 \mathrm{~mm}$. This satisfies the general requirement that the spacing factor should be less than $0.2 \mathrm{~mm}$ to ensure adequate protection against damage from freeze-thaw and scaling due to freezing in the presence of de-icer salts.

The measured aggregate volume fractions also agree reasonably well with the design values. When results from individual polished blocks were examined, it was observed that those from the top of the cylinder relative to the casting direction tend to have higher air contents, higher paste contents and lower aggregate contents than discs from the bottom. Furthermore, the increase in air content is not in proportion with the increase in cement paste content. On average, the volume of air per unit paste for the top disc is about $25 \%$ higher than that of the bottom disc from the same cylinder. This was observed in most samples, for both 0.50 and $0.35 \mathrm{w} / \mathrm{c}$ ratios, and suggests that some segregation has occurred along the length of the cylinder.

Table 2 Results from point-count analysis

\begin{tabular}{|c|c|c|c|c|c|c|c|}
\hline Mix & $\begin{array}{l}\text { Air content } \\
\quad(\%)\end{array}$ & $\begin{array}{c}\text { Paste } \\
\text { content (\%) }\end{array}$ & $\begin{array}{l}\text { Aggregate } \\
\text { content }(\%)\end{array}$ & $\begin{array}{c}\text { Void } \\
\text { frequency } \\
\left(\mathrm{mm}^{-1}\right)\end{array}$ & $\begin{array}{l}\text { Paste-air } \\
\text { ratio }\end{array}$ & $\begin{array}{l}\text { Specific } \\
\text { surface } \\
\left(\mathrm{mm}^{-1}\right)\end{array}$ & $\begin{array}{l}\text { Spacing } \\
\text { factor } \\
\text { (mm) }\end{array}$ \\
\hline C 0.5 & $\begin{array}{c}0.46 \\
(0.18)\end{array}$ & $\begin{array}{c}31.8 \\
(1.20)\end{array}$ & $\begin{array}{c}67.8 \\
(1.47)\end{array}$ & $\begin{array}{c}0.01 \\
(0.00)\end{array}$ & $\begin{array}{c}69.6 \\
(3.40)\end{array}$ & $\begin{array}{c}8.9 \\
(1.30)\end{array}$ & $\begin{array}{c}1.62 \\
(0.04)\end{array}$ \\
\hline C $0.5 \mathrm{~L}$ & $\begin{array}{c}4.35 \\
(0.73)\end{array}$ & $\begin{array}{c}27.7 \\
(1.78)\end{array}$ & $\begin{array}{c}67.9 \\
(1.99)\end{array}$ & $\begin{array}{c}0.49 \\
(0.07)\end{array}$ & $\begin{array}{c}6.4 \\
(1.1)\end{array}$ & $\begin{array}{c}44.9 \\
(1.95)\end{array}$ & $\begin{array}{c}0.12 \\
(0.01)\end{array}$ \\
\hline C $0.5 \mathrm{M}$ & $\begin{array}{c}6.30 \\
(1.34)\end{array}$ & $\begin{array}{c}25.5 \\
(0.34)\end{array}$ & $\begin{array}{c}68.2 \\
(1.63)\end{array}$ & $\begin{array}{c}0.62 \\
(0.05)\end{array}$ & $\begin{array}{c}4.1 \\
(0.94)\end{array}$ & $\begin{array}{c}39.6 \\
(5.68)\end{array}$ & $\begin{array}{c}0.10 \\
(0.00)\end{array}$ \\
\hline C $0.5 \mathrm{H}$ & $\begin{array}{l}11.51 \\
(0.94)\end{array}$ & $\begin{array}{c}23.0 \\
(0.17)\end{array}$ & $\begin{array}{c}65.5 \\
(1.09)\end{array}$ & $\begin{array}{c}1.28 \\
(0.14)\end{array}$ & $\begin{array}{c}2.0 \\
(0.16)\end{array}$ & $\begin{array}{c}44.6 \\
(2.32)\end{array}$ & $\begin{array}{c}0.04 \\
(0.01)\end{array}$ \\
\hline C $0.5 \mathrm{H}^{*}$ & $\begin{array}{c}9.61 \\
(0.65)\end{array}$ & $\begin{array}{c}27.1 \\
(1.21)\end{array}$ & $\begin{array}{c}63.2 \\
(1.83)\end{array}$ & $\begin{array}{c}0.76 \\
(0.08)\end{array}$ & $\begin{array}{c}2.8 \\
(0.09)\end{array}$ & $\begin{array}{c}31.8 \\
(1.54)\end{array}$ & $\begin{array}{c}0.09 \\
(0.01)\end{array}$ \\
\hline $\mathrm{C} 0.5 \mathrm{H}^{+}$ & $\begin{array}{c}8.73 \\
(0.61)\end{array}$ & $\begin{array}{c}31.5 \\
(0.63)\end{array}$ & $\begin{array}{c}59.8 \\
(1.24)\end{array}$ & $\begin{array}{c}0.67 \\
(0.04)\end{array}$ & $\begin{array}{c}3.6 \\
(0.18)\end{array}$ & $\begin{array}{c}30.7 \\
(2.17)\end{array}$ & $\begin{array}{c}0.12 \\
(0.02)\end{array}$ \\
\hline C 0.35 & $\begin{array}{c}1.95 \\
(0.20)\end{array}$ & $\begin{array}{c}30.7 \\
(2.65)\end{array}$ & $\begin{array}{c}67.3 \\
(2.85)\end{array}$ & $\begin{array}{c}0.04 \\
(0.00)\end{array}$ & $\begin{array}{c}15.8 \\
(0.41)\end{array}$ & $\begin{array}{c}7.2 \\
(0.93)\end{array}$ & $\begin{array}{c}1.08 \\
(0.14)\end{array}$ \\
\hline C $0.35 \mathrm{~L}$ & $\begin{array}{c}2.77 \\
(0.27)\end{array}$ & $\begin{array}{c}29.9 \\
(0.85)\end{array}$ & $\begin{array}{c}67.3 \\
(0.87)\end{array}$ & $\begin{array}{c}0.29 \\
(0.01)\end{array}$ & $\begin{array}{l}10.8 \\
(1.1)\end{array}$ & $\begin{array}{c}41.3 \\
(2.73)\end{array}$ & $\begin{array}{c}0.16 \\
(0.00)\end{array}$ \\
\hline C $0.35 \mathrm{~L}^{+}$ & $\begin{array}{c}2.69 \\
(0.81)\end{array}$ & $\begin{array}{c}30.9 \\
(0.29)\end{array}$ & $\begin{array}{c}66.4 \\
(0.87)\end{array}$ & $\begin{array}{c}0.43 \\
(0.06)\end{array}$ & $\begin{array}{c}11.5 \\
(0.78)\end{array}$ & $\begin{array}{c}52.7 \\
(4.37)\end{array}$ & $\begin{array}{c}0.09 \\
(0.02)\end{array}$ \\
\hline C $0.35 \mathrm{M}$ & $\begin{array}{c}5.35 \\
(0.51)\end{array}$ & $\begin{array}{c}25.2 \\
(0.39)\end{array}$ & $\begin{array}{c}69.5 \\
(0.26)\end{array}$ & $\begin{array}{c}0.61 \\
(0.02)\end{array}$ & $\begin{array}{c}4.7 \\
(0.53)\end{array}$ & $\begin{array}{c}45.6 \\
(3.55)\end{array}$ & $\begin{array}{c}0.10 \\
(0.02)\end{array}$ \\
\hline C $0.35 \mathrm{M}^{+}$ & $\begin{array}{c}5.69 \\
(0.39)\end{array}$ & $\begin{array}{c}31.2 \\
(0.66)\end{array}$ & $\begin{array}{c}63.1 \\
(1.03)\end{array}$ & $\begin{array}{c}0.78 \\
(0.01)\end{array}$ & $\begin{array}{c}5.5 \\
(0.28)\end{array}$ & $\begin{array}{c}54.5 \\
(3.16)\end{array}$ & $\begin{array}{c}0.11 \\
(0.00)\end{array}$ \\
\hline C $0.35 \mathrm{H}$ & $\begin{array}{c}8.22 \\
(0.63)\end{array}$ & $\begin{array}{c}24.5 \\
(1.05)\end{array}$ & $\begin{array}{c}67.3 \\
(1.65)\end{array}$ & $\begin{array}{c}0.87 \\
(0.07)\end{array}$ & $\begin{array}{c}3.0 \\
(0.13)\end{array}$ & $\begin{array}{c}42.4 \\
(2.19)\end{array}$ & $\begin{array}{c}0.07 \\
(0.00)\end{array}$ \\
\hline C $0.35 \mathrm{H}^{*}$ & $\begin{array}{c}8.38 \\
(0.56)\end{array}$ & $\begin{array}{c}28.8 \\
(1.53)\end{array}$ & $\begin{array}{c}62.8 \\
(1.82)\end{array}$ & $\begin{array}{c}1.04 \\
(0.08)\end{array}$ & $\begin{array}{c}3.4 \\
(0.22)\end{array}$ & $\begin{array}{c}49.5 \\
(1.69)\end{array}$ & $\begin{array}{c}0.07 \\
(0.00)\end{array}$ \\
\hline $\mathrm{C} 0.35 \mathrm{H}^{+}$ & $\begin{array}{c}7.53 \\
(0.64)\end{array}$ & $\begin{array}{c}31.7 \\
(0.58)\end{array}$ & $\begin{array}{c}60.7 \\
(0.13)\end{array}$ & $\begin{array}{c}0.96 \\
(0.03)\end{array}$ & $\begin{array}{c}4.2 \\
(0.41)\end{array}$ & $\begin{array}{c}51.2 \\
(2.56)\end{array}$ & $\begin{array}{c}0.08 \\
(0.00)\end{array}$ \\
\hline
\end{tabular}

Note: Values in brackets are standard errors. 


\subsection{Microstructure}

224

225

226

227

228

229

230

231

232

233

234

235

Figure 1 shows BSE images of a control concrete containing no air entraining agent and a concrete containing 4.4\% entrained air at the same w/c ratio (0.5) and curing age (7 days). The images show that air entrainment has a significant effect on the microstructure although the amount of entrained air is only a few percent by volume of the sample.

Figure 2 shows the distribution of unreacted cement and porosity from the air void-paste interface. Results are expressed as area percentage of the cement paste. As expected, the w/c $0.35 \mathrm{mix}$ has higher unreacted cement content and lower porosity compared to the w/c $0.50 \mathrm{mix}$. Interestingly, the results clearly show a deficit in cement content near the air voids compared to paste areas farther away. The amount of unreacted cement increases steadily from $\sim 1 \%$ near the air void boundary and reaches a relatively steady value at $30 \mu \mathrm{m}$ away. In contrast, the porosity is high near the boundary and decreases with increasing distance from the air voids. The porosity near the air void-paste interface is approximately two to three times that of the bulk paste region. Visual comparison of the micrographs found less portlandite deposited at the air void-paste interface than at the aggregate-paste interface.

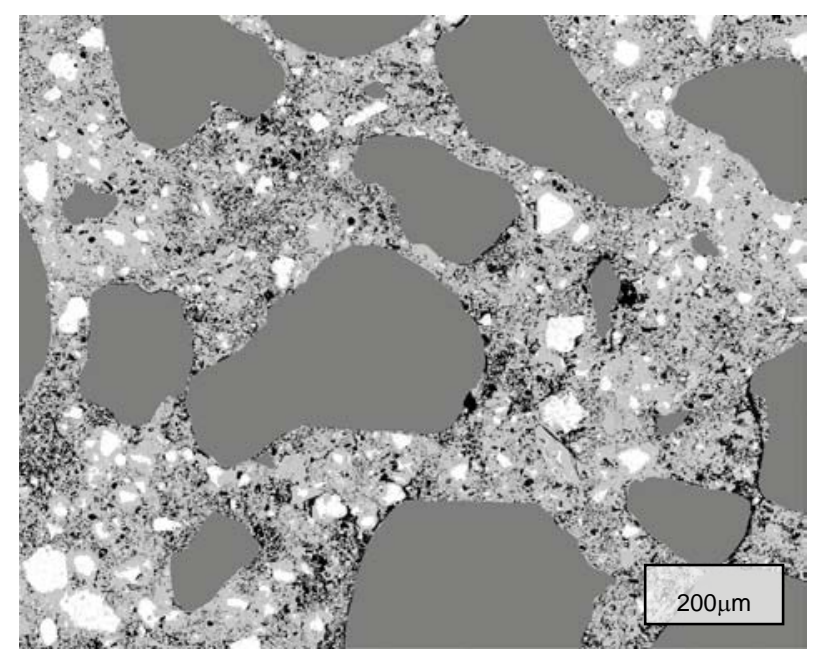

(a) C 0.5

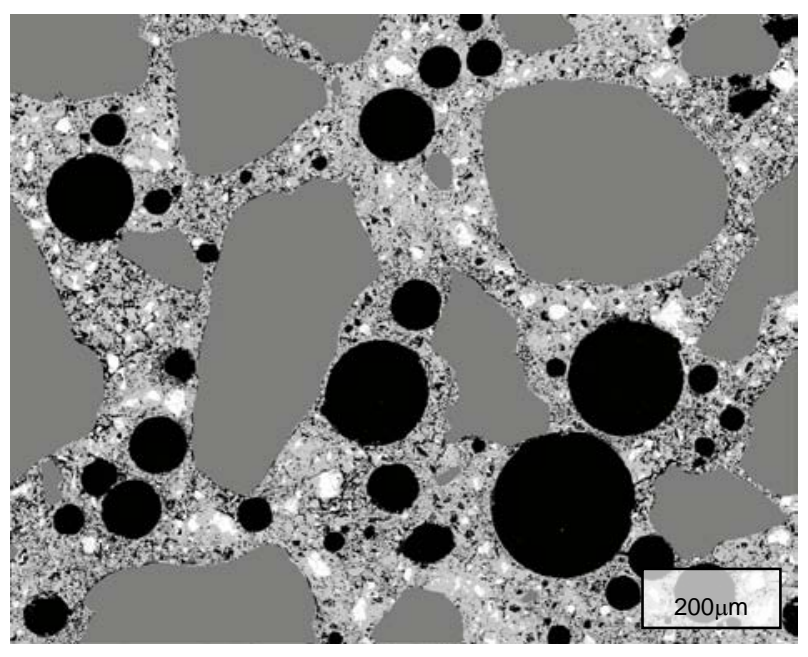

(b) C $0.5 \mathrm{~L}(4.4 \%$ air)

Fig. 1 BSE image of a control concrete (a) and concrete containing entrained air (b). Images were obtained at $100 \times$ magnification (field of view: $1200 \times 960 \mu \mathrm{m}$ ) and segmented to highlight aggregates, unreacted cement, air voids and capillary pores.

For all cases, the width of the affected zone is around $30 \mu \mathrm{m}$ from the air void, with respect to both unreacted cement and porosity. We note that this value is in the range typically reported for the aggregate-cement paste 'interfacial transition zone' of 20-50 $\mu \mathrm{m}$ [19]. Increasing the entrained air content produces sharper gradients. However, the data beyond $50 \mu \mathrm{m}$ for samples containing the highest amount of entrained air are very noisy. This is due to poor counting statistics because the air voids in these samples are so closely spaced that there is very little data available from areas beyond $50 \mu \mathrm{m}$ from the nearest void boundary.

The fraction of cement paste that lies within a certain distance from the nearest air void or aggregate surface was also measured using Euclidean distance mapping, and the results are shown in Fig. 2. The results show that a large fraction 
of the paste in air-entrained concretes would be located in areas where the microstructure is significantly disturbed by the presence of aggregates or air voids. Assuming that the thickness of the ITZ is $30 \mu \mathrm{m}$, increasing the air content from $0.5 \%$ to $8.2 \%$ increases the ITZ fraction from 0.4 to 0.9 . Thus, entrained air voids can significantly increase the heterogeneity of the cement paste microstructure.

\subsection{Transport properties}

Table 3 shows the average oxygen diffusivity, oxygen permeability, water sorptivity and electrical conductivity. The measured data span up to two orders of magnitude for diffusivity and permeability, whereas sorptivity and conductivity values cover one order of magnitude. The variability within replicates is relatively small compared with between different mixes; however, discs from the top of the cylinder tend to have higher transport coefficients than discs from the bottom. This is likely to be a result of segregation, and is consistent with the observation from point-count analysis. It should be noted here that any well-compacted concrete would show some amount of segregation, and we have taken great care not to ignore this effect, but to report it in the paper. This is why replicate measurements were made at different heights and the results averaged. The standard errors of the mean provided in Tables 2 and 3 can be used to generate confidence intervals to show that the variation in the measured values (air content, transport coefficients) within replicates is small compared to variations between the control and mixes with low, medium and high air contents. Thus, differences between mixes are significant, and a meaningful comparison between mixes can be made.

The results indicate a decrease in transport properties with reduction in w/c ratio and with longer curing age. Moisture conditioning prior to testing has a major effect on the measured transport property, in particular for the denser samples (w/c 0.35). Considering the 1-year old samples as an example, drying from $75 \%$ r.h. to $50^{\circ} \mathrm{C}$ increases the diffusivity, permeability and sorptivity coefficients on average by a factor of 13 for the w/c 0.35 samples, and a factor of 3.5 for the w/c 0.5 samples. This is consistent with the fact that gaseous transport and water absorption occur only through empty pores and cracks. Drying increases the accessible transport paths and thus, the transport rates. The w/c 0.35 samples would have a finer pore structure compared to the w/c 0.50 samples, so that for a given conditioning relative humidity, a larger fraction of pore structure remains water-filled due to capillary condensation, according to the Kelvin-Laplace equation. The capillary condensed water is removed upon drying at $50^{\circ} \mathrm{C}$, and this subsequently results in a far greater relative increase in transport for the w/c 0.35 samples.

The above-described trend is reversed for electrical conduction. When measured on saturated specimens, the electrical conductivity is higher than that of specimens conditioned at $75 \%$ r.h. by an average factor of 3 for the w/c 0.35 samples, and a factor of 6 for the w/c 0.5 samples. Drying the samples at $50^{\circ} \mathrm{C}$ decreases the electrical conductivity significantly to an average of $8 \times 10^{-7} \mathrm{~S} / \mathrm{m}$. The electrical conductivity of the w/c 0.35 samples are lower than that of the $0.50 \mathrm{w} / \mathrm{c}$ samples in all cases except when measured at 75\% r.h. This apparently anomalous trend may be due to the finer pore structure in the w/c 0.35 samples and a higher fraction of the pores being water-filled following conditioning at $75 \%$ r.h., which provides a more continuous conduction path in comparison with the w/c 0.50 samples. 


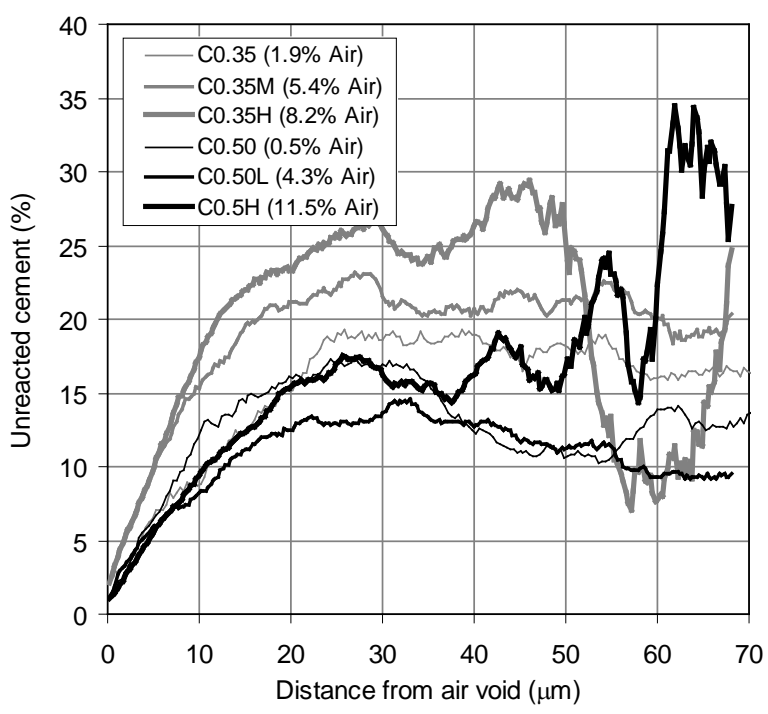

(a)

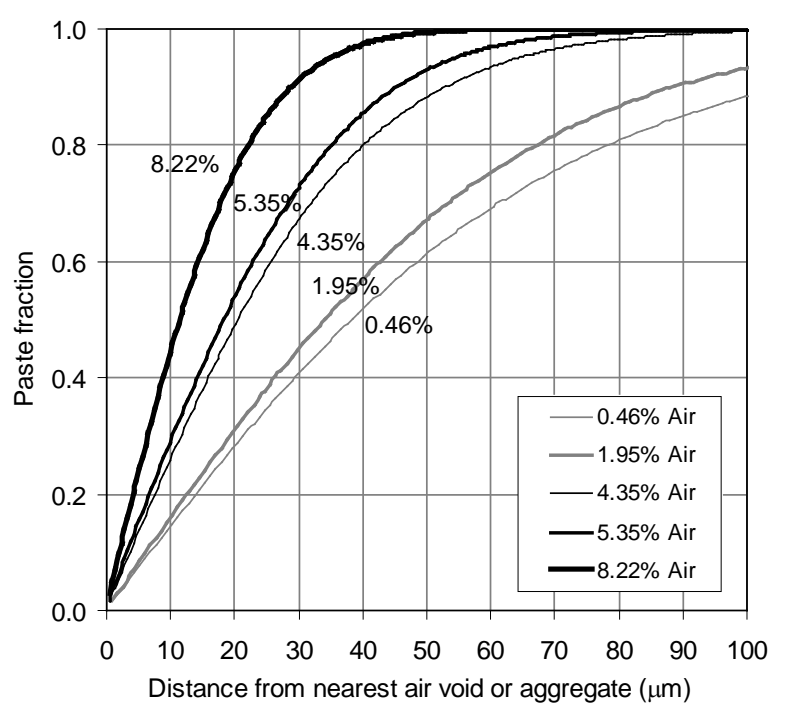

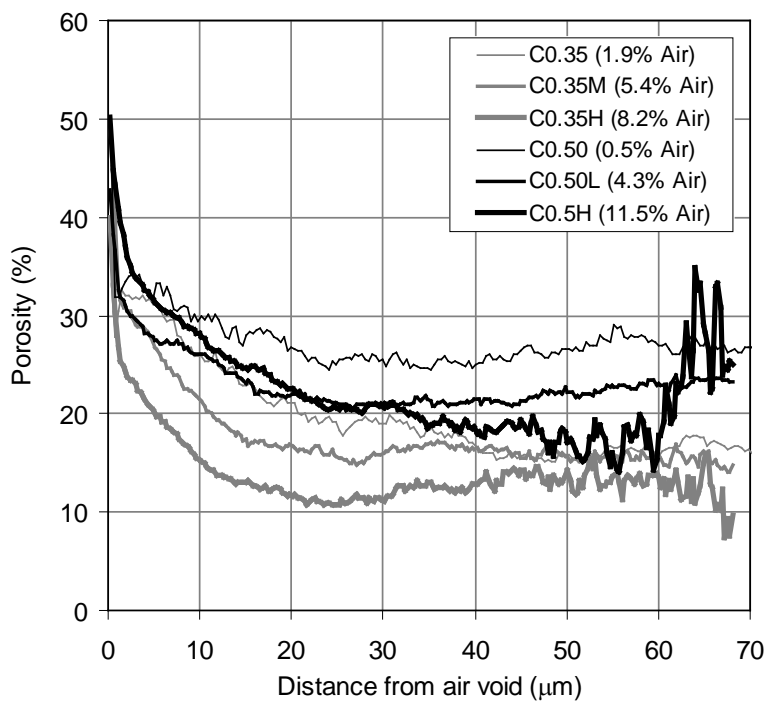

(b)

(c)

Fig. 2 Gradients of unreacted cement content (a) and detectable porosity (b) measured from the air void-paste interface of 7-day cured samples. Figure (c) shows the influence of air content on the fraction of cement paste that is located within a given distance from the nearest air void or aggregate particle. Values are averages of 30 frames.

Figure 3 shows the transport coefficients normalised to those of the control samples, so as to highlight the effect of air entrainment. Despite some scatter, the data clearly show an increase in gaseous diffusivity and permeability (Fig. 3a, b) with increasing air content, regardless of the w/c ratio, curing age and conditioning regime. The diffusivity and permeability of concretes with the highest air contents can be up to 2-3 times higher than that of the control. The effect of air entrainment is similar to increasing w/c ratio from 0.35 to 0.50 if samples are dried to remove most of the moisture in capillary pores prior to testing. For example, referring to Table 3, the diffusivity and permeability of $\mathrm{C} 0.35$ $\mathrm{H}(8.22 \%$ air $)$ is very close to $\mathrm{C} 0.5$ when the tests are carried out after drying at either $52 \%$ r.h. or $50^{\circ} \mathrm{C}$. 
299 The effect of entrained air on sorptivity is less consistent, although a greater number of data points showed a decreasing 300 rather than an increasing trend (Fig. 3c). Except for the 1-year cured samples conditioned at 75\% r.h. that displayed a 301 mild increase in sorptivity, other samples showed a decrease in sorptivity with increasing air content. For electrical 302 conductivity, two trends are clearly visible (Fig. 3d). Samples that were tested after conditioning at 75\% r.h. or completion of the sorptivity measurement showed a reduction in electrical conductivity with increasing air content. However, samples that were vacuum-saturated showed a significant rise in conductivity regardless of the w/c ratio.

The bulk porosities of the 1-year cured samples measured by water absorption are also given in Table 3. Porosity was determined twice, the first on the completion of the sorptivity test and the second, after vacuum saturation. The first set of porosity data display no significant change with air content; in fact, the values for samples containing entrained air are lower than expected. The second set of data show that the measured porosity increases with air content, at a rate approximately equal to the air content. This suggests that upon completion of the sorptivity test, the air voids remain mostly empty and hence non-conducting, but subsequently become water-filled when the sample is treated under vacuum. The saturated air voids are then able to contribute to electrical conduction, which explains the observed increase in conductivity (Fig. 3d). 
Table 3 Results - $\mathrm{O}_{2}$ diffusivity, $\mathrm{O}_{2}$ permeability, sorptivity, electrical conductivity and porosity from water absorption

\begin{tabular}{|c|c|c|c|c|c|c|c|c|c|c|c|c|c|c|c|c|}
\hline \multirow{2}{*}{ Mix } & \multirow{2}{*}{$\begin{array}{l}\text { Air } \\
(\%)\end{array}$} & \multicolumn{3}{|c|}{$\mathrm{O}_{2}$ diffusivity $\left(\mathrm{m}^{2} / \mathrm{s}\right)$} & \multicolumn{3}{|c|}{$\mathrm{O}_{2}$ permeability $\left(\mathrm{m}^{2}\right)$} & \multicolumn{3}{|c|}{ Sorptivity $\left(\mathrm{g} / \mathrm{m}^{2} \cdot \mathrm{min}^{0.5}\right)$} & \multicolumn{4}{|c|}{ Conductivity $\left(\times 10^{-3} \mathrm{~S} / \mathrm{m}\right)$} & \multicolumn{2}{|c|}{ Porosity (\%) } \\
\hline & & $\begin{array}{c}\text { 7d: } \\
52 \% \text { rh }\end{array}$ & $\begin{array}{c}\text { 1yr: } \\
75 \% \text { rh }\end{array}$ & $\begin{array}{l}\text { 1yr: } \\
50^{\circ} \mathrm{C}\end{array}$ & $\begin{array}{c}\text { 7d: } \\
52 \% \text { rh }\end{array}$ & $\begin{array}{c}\text { 1yr: } \\
75 \% \text { rh }\end{array}$ & $\begin{array}{l}\text { 1yr: } \\
50^{\circ} \mathrm{C}\end{array}$ & $\begin{array}{c}\text { 7d: } \\
52 \% \text { rh }\end{array}$ & $\begin{array}{c}\text { 1yr: } \\
75 \% \text { rh }\end{array}$ & $\begin{array}{l}\text { 1yr: } \\
50^{\circ} \mathrm{C}\end{array}$ & 7d (I) & $\begin{array}{l}1 \mathrm{yr} \\
\text { (II) }\end{array}$ & $\begin{array}{l}1 \mathrm{yr} \\
\text { (I) }\end{array}$ & $\begin{array}{l}1 \mathrm{yr} \\
\text { (III) }\end{array}$ & $\begin{array}{l}\text { 1yr } \\
\text { (I) }\end{array}$ & $\begin{array}{l}1 \mathrm{yr} \\
\text { (III) }\end{array}$ \\
\hline С 0.5 & $\begin{array}{c}0.46 \\
(0.18)\end{array}$ & $\begin{array}{c}7.27 \mathrm{E}-8 \\
(0.55 \mathrm{E}-8)\end{array}$ & $\begin{array}{c}2.22 \mathrm{E}-8 \\
(0.06 \mathrm{E}-8)\end{array}$ & $\begin{array}{c}1.01 \mathrm{E}-7 \\
(0.02 \mathrm{E}-7)\end{array}$ & $\begin{array}{c}1.30 \mathrm{E}-16 \\
(0.06 \mathrm{E}-16)\end{array}$ & $\begin{array}{c}5.36 \mathrm{E}-17 \\
(0.07 \mathrm{E}-17)\end{array}$ & $\begin{array}{c}1.88 \mathrm{E}-16 \\
(0.17 \mathrm{E}-16)\end{array}$ & & $\begin{array}{l}32.1 \\
(1.8)\end{array}$ & $\begin{array}{l}156.1 \\
(22.4)\end{array}$ & $\begin{array}{c}8.96 \\
(0.11)\end{array}$ & $\begin{array}{c}3.56 \\
(0.10)\end{array}$ & $\begin{array}{c}7.94 \\
(0.03)\end{array}$ & $\begin{array}{c}8.39 \\
(0.46))\end{array}$ & $\begin{array}{c}9.0 \\
(0.2)\end{array}$ & $\begin{array}{l}10.2 \\
(0.3)\end{array}$ \\
\hline C $0.5 \mathrm{~L}$ & $\begin{array}{c}4.35 \\
(0.73)\end{array}$ & $\begin{array}{c}1.51 \mathrm{E}-7 \\
(0.25 \mathrm{E}-7)\end{array}$ & $\begin{array}{c}4.86 \mathrm{E}-8 \\
(0.34 \mathrm{E}-8)\end{array}$ & $\begin{array}{c}2.07 \mathrm{E}-7 \\
(0.19 \mathrm{E}-7)\end{array}$ & $\begin{array}{c}2.11 \mathrm{E}-16 \\
(0.58 \mathrm{E}-16)\end{array}$ & $\begin{array}{c}7.54 \mathrm{E}-17 \\
(0.18 \mathrm{E}-17)\end{array}$ & $\begin{array}{c}2.43 \mathrm{E}-16 \\
(0.32 \mathrm{E}-16)\end{array}$ & $\begin{array}{l}129.0 \\
(13.0)\end{array}$ & $\begin{array}{l}39.7 \\
(1.9)\end{array}$ & $\begin{array}{l}151.0 \\
(28.7)\end{array}$ & $\begin{array}{c}8.47 \\
(0.10)\end{array}$ & $\begin{array}{c}3.26 \\
(0.28)\end{array}$ & $\begin{array}{c}7.91 \\
(0.21)\end{array}$ & $\begin{array}{c}14.6 \\
(0.35)\end{array}$ & $\begin{array}{c}9.7 \\
(1.1)\end{array}$ & $\begin{array}{l}14.4 \\
(0.9)\end{array}$ \\
\hline C $0.5 \mathrm{M}$ & $\begin{array}{c}6.30 \\
(1.34)\end{array}$ & $\begin{array}{c}2.31 \mathrm{E}-7 \\
(0.36 \mathrm{E}-7)\end{array}$ & $\begin{array}{c}7.68 \mathrm{E}-8 \\
(0.66 \mathrm{E}-8)\end{array}$ & $\begin{array}{c}2.70 \mathrm{E}-7 \\
(0.41 \mathrm{E}-7)\end{array}$ & $\begin{array}{c}2.48 \mathrm{E}-16 \\
(0.40 \mathrm{E}-16)\end{array}$ & $\begin{array}{c}1.19 \mathrm{E}-16 \\
(0.21 \mathrm{E}-16)\end{array}$ & $\begin{array}{c}3.15 \mathrm{E}-16 \\
(0.77 \mathrm{E}-16)\end{array}$ & $\begin{array}{l}118.7 \\
(12.5)\end{array}$ & $\begin{array}{l}38.0 \\
(2.5)\end{array}$ & $\begin{array}{l}100.4 \\
(14.5)\end{array}$ & $\begin{array}{c}6.74 \\
(0.10)\end{array}$ & $\begin{array}{c}2.68 \\
(0.21)\end{array}$ & $\begin{array}{c}6.15 \\
(0.25)\end{array}$ & $\begin{array}{c}17.6 \\
(0.12)\end{array}$ & $\begin{array}{c}8.8 \\
(0.7)\end{array}$ & $\begin{array}{l}16.5 \\
(1.1)\end{array}$ \\
\hline C $0.5 \mathrm{H}$ & $\begin{array}{l}11.51 \\
(0.94)\end{array}$ & $\begin{array}{c}1.85 \mathrm{E}-7 \\
(0.24 \mathrm{E}-7)\end{array}$ & $\begin{array}{c}7.41 \mathrm{E}-8 \\
(0.48 \mathrm{E}-8)\end{array}$ & $\begin{array}{c}2.56 \mathrm{E}-7 \\
(0.18 \mathrm{E}-7)\end{array}$ & $\begin{array}{c}2.25 \mathrm{E}-16 \\
(0.36 \mathrm{E}-16)\end{array}$ & $\begin{array}{c}1.30 \mathrm{E}-16 \\
(0.13 \mathrm{E}-16)\end{array}$ & $\begin{array}{c}3.86 \mathrm{E}-16 \\
(0.61 \mathrm{E}-16)\end{array}$ & $\begin{array}{l}100.1 \\
(6.2)\end{array}$ & $\begin{array}{l}35.5 \\
(2.9)\end{array}$ & $\begin{array}{l}97.1 \\
(6.4)\end{array}$ & $\begin{array}{c}5.45 \\
(0.41)\end{array}$ & $\begin{array}{c}2.17 \\
(0.17)\end{array}$ & $\begin{array}{c}5.05 \\
(0.15)\end{array}$ & $\begin{array}{c}17.9 \\
(0.42)\end{array}$ & $\begin{array}{c}8.0 \\
(0.7)\end{array}$ & $\begin{array}{l}19.7 \\
(1.3)\end{array}$ \\
\hline C $0.5 \mathrm{H}^{*}$ & $\begin{array}{c}9.61 \\
(0.65)\end{array}$ & $\begin{array}{c}2.56 \mathrm{E}-7 \\
0.38 \mathrm{E}-7)\end{array}$ & $\begin{array}{c}8.82 \mathrm{E}-8 \\
(0.84 \mathrm{E}-8)\end{array}$ & $\begin{array}{c}2.98 \mathrm{E}-7 \\
(0.51 \mathrm{E}-7)\end{array}$ & $\begin{array}{c}3.06 \mathrm{E}-16 \\
(0.65 \mathrm{E}-16)\end{array}$ & $\begin{array}{c}1.50 \mathrm{E}-16 \\
(0.25 \mathrm{E}-16)\end{array}$ & $\begin{array}{c}4.19 \mathrm{E}-16 \\
(0.57 \mathrm{E}-16)\end{array}$ & $\begin{array}{l}140.2 \\
(15.2)\end{array}$ & $\begin{array}{l}37.6 \\
(3.1)\end{array}$ & $\begin{array}{l}131.8 \\
(23.0)\end{array}$ & $\begin{array}{c}7.42 \\
(0.12)\end{array}$ & $\begin{array}{c}2.88 \\
(0.19)\end{array}$ & $\begin{array}{c}5.95 \\
(0.24)\end{array}$ & $\begin{array}{c}18.8 \\
(0.30)\end{array}$ & $\begin{array}{l}10.5 \\
(0.6)\end{array}$ & $\begin{array}{l}20.9 \\
(1.9)\end{array}$ \\
\hline $\mathrm{C} 0.5 \mathrm{H}^{+}$ & $\begin{array}{c}8.73 \\
(0.61)\end{array}$ & $\begin{array}{c}1.57 \mathrm{E}-7 \\
(0.26 \mathrm{E}-7)\end{array}$ & $\begin{array}{c}7.36 \mathrm{E}-8 \\
(0.78 \mathrm{E}-8)\end{array}$ & $\begin{array}{c}2.26 \mathrm{E}-7 \\
(0.30 \mathrm{E}-7)\end{array}$ & $\begin{array}{c}1.95 \mathrm{E}-16 \\
(0.41 \mathrm{E}-16)\end{array}$ & $\begin{array}{c}1.62 \mathrm{E}-16 \\
(0.35 \mathrm{E}-16)\end{array}$ & $\begin{array}{c}3.64 \mathrm{E}-16 \\
(0.34 \mathrm{E}-16)\end{array}$ & $\begin{array}{l}138.5 \\
(14.7)\end{array}$ & $\begin{array}{l}37.8 \\
(2.8) \\
\end{array}$ & $\begin{array}{l}156.4 \\
(21.7)\end{array}$ & $\begin{array}{c}7.91 \\
(0.11)\end{array}$ & $\begin{array}{c}2.43 \\
(0.13)\end{array}$ & $\begin{array}{c}5.80 \\
(0.10)\end{array}$ & $\begin{array}{c}17.7 \\
(0.16)\end{array}$ & $\begin{array}{l}10.8 \\
(0.9)\end{array}$ & $\begin{array}{l}20.4 \\
(1.8)\end{array}$ \\
\hline C 0.35 & $\begin{array}{c}1.95 \\
(0.20)\end{array}$ & $\begin{array}{c}2.78 \mathrm{E}-8 \\
(0.14 \mathrm{E}-8)\end{array}$ & $\begin{array}{c}3.96 \mathrm{E}-9 \\
(0.96 \mathrm{E}-9)\end{array}$ & $\begin{array}{c}5.95 \mathrm{E}-8 \\
(0.46 \mathrm{E}-8)\end{array}$ & $\begin{array}{c}6.46 \mathrm{E}-17 \\
(0.33 \mathrm{E}-17)\end{array}$ & $\begin{array}{c}7.90 \mathrm{E}-18 \\
(0.67 \mathrm{E}-18)\end{array}$ & $\begin{array}{c}9.38 \mathrm{E}-17 \\
(0.63 \mathrm{E}-17)\end{array}$ & $\begin{array}{l}62.0 \\
(1.3)\end{array}$ & $\begin{array}{c}6.4 \\
(0.5)\end{array}$ & $\begin{array}{l}104.8 \\
(2.9)\end{array}$ & $\begin{array}{c}5.76 \\
(0.40)\end{array}$ & $\begin{array}{c}3.63 \\
(0.07)\end{array}$ & $\begin{array}{c}4.46 \\
(0.00)\end{array}$ & $\begin{array}{c}5.38 \\
(0.08)\end{array}$ & $\begin{array}{c}6.2 \\
(0.4)\end{array}$ & $\begin{array}{c}7.3 \\
(0.6)\end{array}$ \\
\hline C $0.35 \mathrm{~L}$ & $\begin{array}{c}2.77 \\
(0.27)\end{array}$ & $\begin{array}{c}3.95 E-8 \\
(0.42 E-8)\end{array}$ & $\begin{array}{c}5.66 \mathrm{E}-9 \\
(0.87 \mathrm{E}-9)\end{array}$ & $\begin{array}{c}6.57 \mathrm{E}-8 \\
(0.29 \mathrm{E}-8)\end{array}$ & $\begin{array}{c}1.05 \mathrm{E}-16 \\
(0.34 \mathrm{E}-16)\end{array}$ & $\begin{array}{c}1.73 \mathrm{E}-17 \\
(0.45 \mathrm{E}-17)\end{array}$ & $\begin{array}{c}9.78 \mathrm{E}-17 \\
(0.42 \mathrm{E}-17)\end{array}$ & $\begin{array}{l}62.8 \\
(3.7)\end{array}$ & $\begin{array}{c}6.4 \\
(0.7)\end{array}$ & $\begin{array}{l}102.9 \\
(9.2)\end{array}$ & $\begin{array}{c}4.62 \\
(0.57)\end{array}$ & $\begin{array}{c}3.02 \\
(0.19)\end{array}$ & $\begin{array}{c}4.38 \\
(0.03)\end{array}$ & $\begin{array}{c}7.22 \\
(0.01)\end{array}$ & $\begin{array}{c}5.5 \\
(0.2)\end{array}$ & $\begin{array}{c}9.6 \\
(0.7)\end{array}$ \\
\hline C $0.35 \mathrm{~L}^{+}$ & $\begin{array}{c}2.69 \\
(0.81)\end{array}$ & $\begin{array}{c}3.52 \mathrm{E}-8 \\
(0.19 \mathrm{E}-8)\end{array}$ & $\begin{array}{c}5.77 \mathrm{E}-9 \\
(0.52 \mathrm{E}-9)\end{array}$ & $\begin{array}{c}6.80 \mathrm{E}-8 \\
(0.03 \mathrm{E}-8)\end{array}$ & $\begin{array}{c}7.05 \mathrm{E}-17 \\
(0.27 \mathrm{E}-17)\end{array}$ & $\begin{array}{c}9.56 \mathrm{E}-18 \\
(0.35 \mathrm{E}-18)\end{array}$ & $\begin{array}{c}9.23 \mathrm{E}-17 \\
(0.56 \mathrm{E}-17)\end{array}$ & $\begin{array}{l}62.3 \\
(1.5)\end{array}$ & $\begin{array}{c}6.7 \\
(0.2)\end{array}$ & $\begin{array}{l}100.1 \\
(4.5)\end{array}$ & $\begin{array}{c}5.51 \\
(0.34)\end{array}$ & $\begin{array}{c}3.39 \\
(0.03)\end{array}$ & $\begin{array}{c}3.72 \\
(0.20)\end{array}$ & $\begin{array}{c}7.44 \\
(0.12)\end{array}$ & $\begin{array}{c}6.0 \\
(0.2)\end{array}$ & $\begin{array}{l}10.1 \\
(1.0)\end{array}$ \\
\hline C $0.35 \mathrm{M}$ & $\begin{array}{c}5.35 \\
(0.51)\end{array}$ & $\begin{array}{c}3.98 \mathrm{E}-8 \\
(0.36 \mathrm{E}-8)\end{array}$ & $\begin{array}{c}5.94 \mathrm{E}-9 \\
(0.44 \mathrm{E}-9)\end{array}$ & $\begin{array}{c}7.46 \mathrm{E}-8 \\
(0.29 \mathrm{E}-8)\end{array}$ & $\begin{array}{c}1.23 \mathrm{E}-16 \\
(0.26 \mathrm{E}-16)\end{array}$ & $\begin{array}{c}9.66 \mathrm{E}-18 \\
(0.22 \mathrm{E}-18)\end{array}$ & $\begin{array}{c}1.28 \mathrm{E}-16 \\
(0.22 \mathrm{E}-16)\end{array}$ & $\begin{array}{l}52.1 \\
(0.4)\end{array}$ & $\begin{array}{l}7.0 \\
(0.5)\end{array}$ & $\begin{array}{l}96.2 \\
(5.0)\end{array}$ & $\begin{array}{c}4.37 \\
(0.24)\end{array}$ & $\begin{array}{c}3.08 \\
(0.05)\end{array}$ & $\begin{array}{c}3.63 \\
(0.06)\end{array}$ & $\begin{array}{c}8.49 \\
(0.02)\end{array}$ & $\begin{array}{c}4.9 \\
(0.3)\end{array}$ & $\begin{array}{l}11.7 \\
(0.9)\end{array}$ \\
\hline C $0.35 \mathrm{M}^{+}$ & $\begin{array}{c}5.69 \\
(0.39)\end{array}$ & $\begin{array}{c}4.54 \mathrm{E}-8 \\
(0.68 \mathrm{E}-8)\end{array}$ & $\begin{array}{c}7.48 \mathrm{E}-9 \\
(0.11 \mathrm{E}-9)\end{array}$ & $\begin{array}{c}9.64 \mathrm{E}-8 \\
(0.18 \mathrm{E}-8)\end{array}$ & $\begin{array}{c}9.06 \mathrm{E}-17 \\
(0.19 \mathrm{E}-17)\end{array}$ & $\begin{array}{c}1.33 \mathrm{E}-17 \\
(0.10 \mathrm{E}-17)\end{array}$ & $\begin{array}{c}1.03 \mathrm{E}-16 \\
(0.16 \mathrm{E}-16)\end{array}$ & $\begin{array}{l}57.4 \\
(2.8)\end{array}$ & $\begin{array}{c}7.5 \\
(0.8)\end{array}$ & $\begin{array}{l}105.6 \\
(8.8)\end{array}$ & $\begin{array}{c}4.23 \\
(0.40)\end{array}$ & $\begin{array}{c}3.30 \\
(0.11)\end{array}$ & $\begin{array}{c}3.99 \\
(0.12)\end{array}$ & $\begin{array}{c}9.46 \\
(0.04)\end{array}$ & $\begin{array}{c}6.5 \\
(0.4)\end{array}$ & $\begin{array}{l}12.5 \\
(0.8)\end{array}$ \\
\hline $\mathrm{C} 0.35 \mathrm{H}$ & $\begin{array}{c}8.22 \\
(0.63)\end{array}$ & $\begin{array}{c}7.49 \mathrm{E}-8 \\
(0.34 \mathrm{E}-8)\end{array}$ & $\begin{array}{c}6.11 \mathrm{E}-9 \\
(0.70 \mathrm{E}-9)\end{array}$ & $\begin{array}{c}9.31 \mathrm{E}-8 \\
(0.78 \mathrm{E}-8)\end{array}$ & $\begin{array}{c}1.22 \mathrm{E}-16 \\
(0.03 \mathrm{E}-16)\end{array}$ & $\begin{array}{c}1.17 \mathrm{E}-17 \\
(0.21 \mathrm{E}-17)\end{array}$ & $\begin{array}{c}1.72 \mathrm{E}-16 \\
(0.30 \mathrm{E}-16)\end{array}$ & $\begin{array}{l}45.4 \\
(2.4)\end{array}$ & $\begin{array}{l}7.7 \\
(0.8)\end{array}$ & $\begin{array}{l}69.8 \\
(3.8)\end{array}$ & $\begin{array}{c}3.77 \\
(0.30)\end{array}$ & $\begin{array}{c}2.59 \\
(0.16)\end{array}$ & $\begin{array}{c}3.61 \\
(0.13)\end{array}$ & $\begin{array}{c}9.56 \\
(0.22)\end{array}$ & $\begin{array}{c}4.5 \\
(0.3)\end{array}$ & $\begin{array}{l}14.5 \\
(1.2)\end{array}$ \\
\hline C $0.35 \mathrm{H}^{*}$ & $\begin{array}{c}8.38 \\
(0.56)\end{array}$ & $\begin{array}{c}5.52 \mathrm{E}-8 \\
(0.15 \mathrm{E}-8)\end{array}$ & $\begin{array}{c}6.92 \mathrm{E}-9 \\
(0.89 \mathrm{E}-9)\end{array}$ & $\begin{array}{c}1.02 \mathrm{E}-7 \\
(0.05 \mathrm{E}-8)\end{array}$ & $\begin{array}{c}1.17 \mathrm{E}-16 \\
(0.18 \mathrm{E}-16)\end{array}$ & $\begin{array}{c}1.03 \mathrm{E}-17 \\
(0.28 \mathrm{E}-17)\end{array}$ & $\begin{array}{c}1.91 \mathrm{E}-16 \\
(0.27 \mathrm{E}-16)\end{array}$ & $\begin{array}{l}51.2 \\
(1.7)\end{array}$ & $\begin{array}{c}6.5 \\
(0.7)\end{array}$ & $\begin{array}{l}97.5 \\
(7.6)\end{array}$ & $\begin{array}{c}4.76 \\
(0.31)\end{array}$ & $\begin{array}{c}2.84 \\
(0.04)\end{array}$ & $\begin{array}{c}3.31 \\
(0.06)\end{array}$ & $\begin{array}{c}12.0 \\
(0.04)\end{array}$ & $\begin{array}{c}5.1 \\
(0.3)\end{array}$ & $\begin{array}{l}16.7 \\
(1.4)\end{array}$ \\
\hline $\mathrm{C} 0.35 \mathrm{H}^{+}$ & $\begin{array}{c}7.53 \\
(0.64)\end{array}$ & $\begin{array}{c}4.76 \mathrm{E}-8 \\
(0.24 \mathrm{E}-8)\end{array}$ & $\begin{array}{c}6.50 \mathrm{E}-9 \\
(0.11 \mathrm{E}-9)\end{array}$ & $\begin{array}{c}9.76 \mathrm{E}-8 \\
(0.10 \mathrm{E}-8)\end{array}$ & $\begin{array}{c}8.37 \mathrm{E}-17 \\
(0.28 \mathrm{E}-17)\end{array}$ & $\begin{array}{c}1.05 \mathrm{E}-17 \\
(0.37 \mathrm{E}-17)\end{array}$ & $\begin{array}{c}1.46 \mathrm{E}-16 \\
(0.50 \mathrm{E}-16)\end{array}$ & $\begin{array}{l}55.7 \\
(2.1)\end{array}$ & $\begin{array}{c}7.2 \\
(0.7)\end{array}$ & $\begin{array}{l}94.7 \\
(0.4)\end{array}$ & $\begin{array}{c}5.21 \\
(0.05)\end{array}$ & $\begin{array}{c}3.21 \\
(0.02)\end{array}$ & $\begin{array}{c}3.34 \\
(0.05)\end{array}$ & $\begin{array}{l}10.7 \\
(0.30)\end{array}$ & $\begin{array}{c}6.8 \\
(0.2)\end{array}$ & $\begin{array}{l}15.3 \\
(1.3)\end{array}$ \\
\hline
\end{tabular}

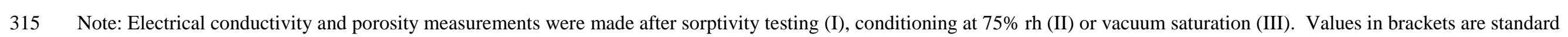
316 errors. 


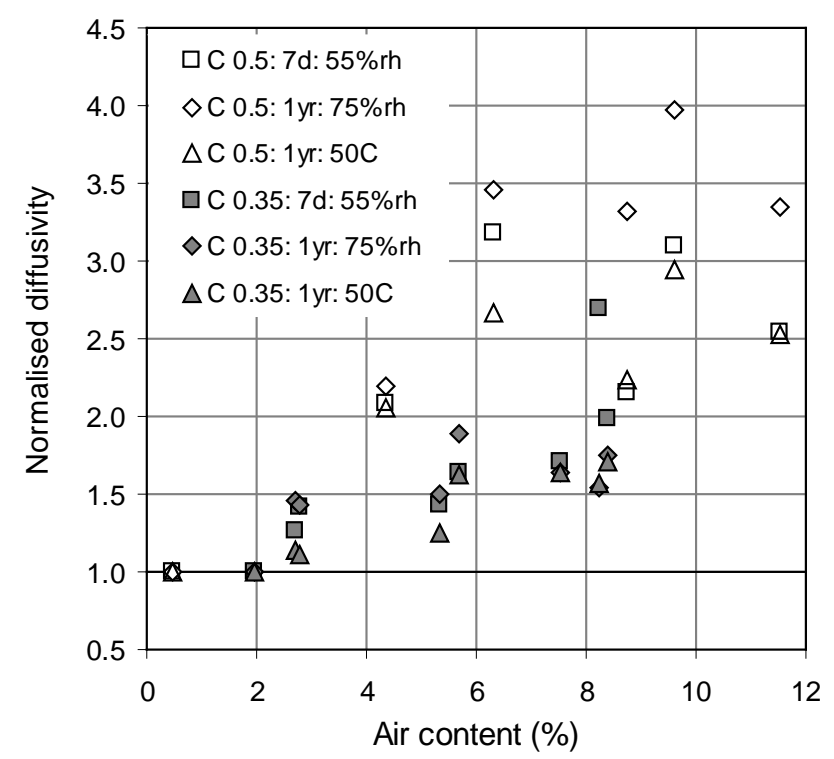

(a)

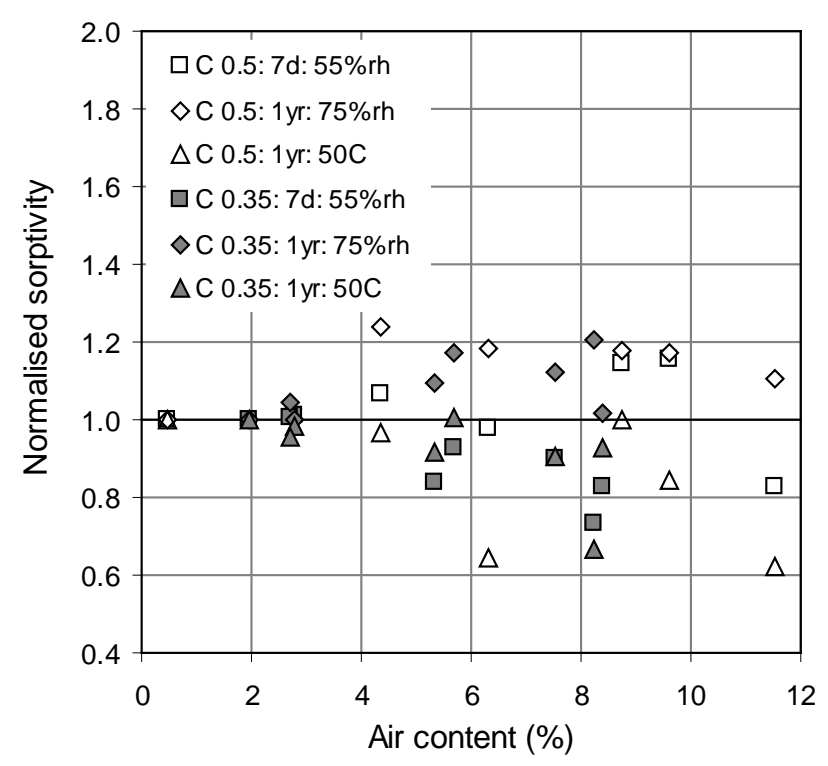

(c)

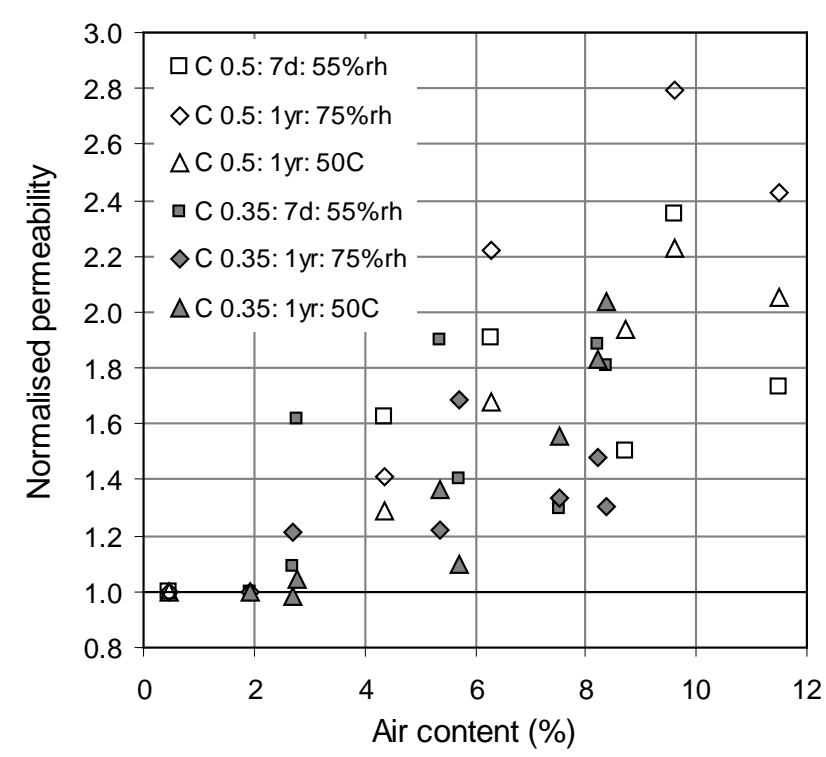

(b)

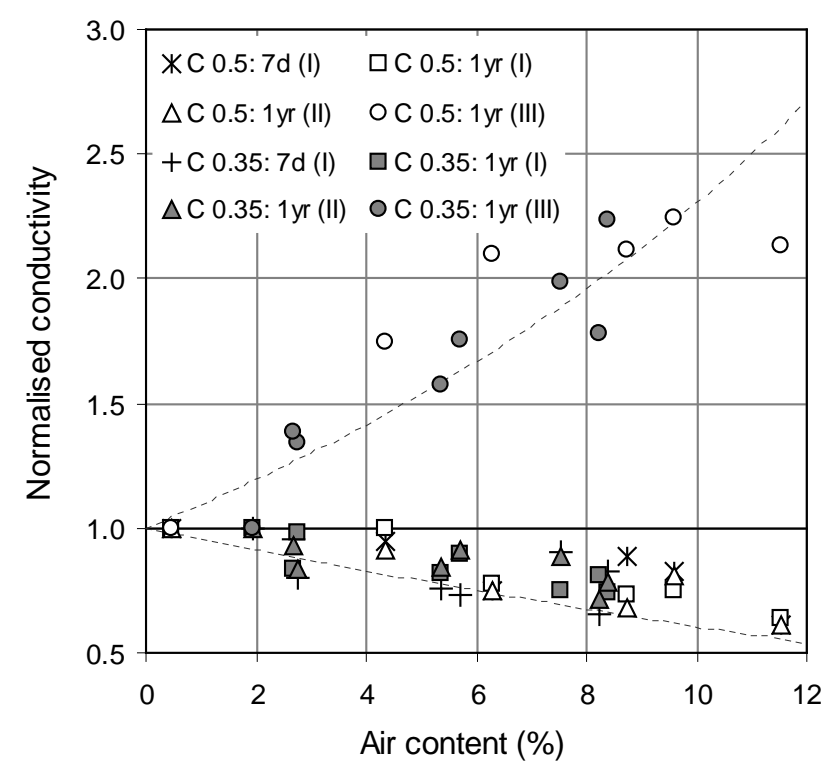

(d)

Fig. 3 Scatter plots showing the effect of air content on oxygen diffusivity (a), oxygen permeability (b), water sorptivity (c) and electrical conductivity (d). The data are normalised to that of the control. For electrical conductivity, measurements were made after sorptivity testing (I), conditioning at $75 \%$ rh (II) or vacuum saturation (III). The dotted lines in (d) are from equations (2) and (3).

\subsection{Modelling}

In this section, we will attempt to relate the transport properties of the air-entrained concrete to that of the control concrete using homogenization principles, in order to gain further insights into the influence of air voids. This is carried out in three stages (Fig. 4) and we begin by considering air voids as spherical inclusions randomly distributed in a continuous porous cement paste matrix through which transport predominantly occurs (Fig. 4a). In reality, the paste matrix is a heterogeneous mixture of hydration products, unreacted cement and pore space, but we will treat this as a uniform phase for simplicity. There are numerous effective media schemes that describe the macroscopic effective 
properties of such binary composites as a function of the properties and volume fractions of its components. One of the most widely used is the classical Maxwell's approximation, which, for a composite containing spherical inclusions, is written as:

$$
\frac{\sigma_{e}-\sigma_{m}}{\sigma_{e}+2 \sigma_{m}}=f_{i}\left(\frac{\sigma_{i}-\sigma_{m}}{\sigma_{i}+2 \sigma_{m}}\right)
$$

where $\sigma_{e}$ is the effective conductivity of the composite, $\sigma_{m}$ is the conductivity of the continuous phase (matrix), and $\sigma_{i}$ and $f_{i}$ are the conductivity and volume fraction of the discrete phase (inclusion). This is an extension of the ClausiusMossotti relation and is often referred to as the Maxwell-Garnett approximation [20-23]. Maxwell's equation is valid for composites with spherical inclusions at sufficiently low concentrations such that they do not overlap or percolate, and thus befits the composite described above. Moreover, the relation coincides with one of the well-known HashinShtrikman [24] upper and lower bounds for a macroscopically homogeneous and isotropic medium. We also note that this equation has been used to model the influence of aggregate content on the electrical conductivity of concrete with a good agreement obtained [25].

It may be noted from Figure 1 that although the air voids are nearly spherical, the aggregate particles are somewhat angular, and can be more reasonably idealised as spheroids with aspect ratios between, say, 0.5 and 2.0. But it is known [26] that if Maxwell's equation is extended to the case of spheroidal inclusions, the results are insensitive to the aspect ratio if it lies in the range of 0.5-2.0.

The air voids may be empty, partially saturated, or water-filled, but we assume that the property contrast between paste matrix and air voids is high such that the ratio $\sigma_{i} / \sigma_{m}$ tends either to zero or to infinity. Thus, air voids act as either superconducting or perfectly insulating inclusions, depending on its moisture state and the transport property of interest. For the case of superconducting inclusions $\left(\sigma_{i} / \sigma_{m}=\infty\right)$, Maxwell's equation for a three-dimensional composite simplifies to

$$
\frac{\sigma_{P o}}{\sigma_{P}}=\frac{1+2 f_{o}}{1-f_{o}}
$$

where $\sigma_{P o}$ is the effective conductivity of the paste-void composite, $\sigma_{P}$ is the conductivity of the paste matrix and $f_{o}$ is the volume fraction of the air voids. The corresponding Maxwell's equation for the case of non-conducting inclusions $\left(\sigma_{i} / \sigma_{m}=0\right)$ is

$$
\frac{\sigma_{P o}}{\sigma_{P}}=\frac{1-f_{o}}{1+0.5 f_{o}}
$$

The second step is the determination of the conductivity of the control concrete (Fig. 4b), where only the aggregates and cement paste matrix are considered. Here, we assume that the aggregates are dense compared to the paste matrix, and so have negligible contribution to transport $\left(\sigma_{i} / \sigma_{m}=0\right)$. Thus:

$$
\frac{\sigma_{C}}{\sigma_{P}}=\frac{1-f_{A}}{1+0.5 f_{A}}
$$


where $\sigma_{C}$ is the effective conductivity of the control concrete, and $f_{A}$ is the aggregate volume fraction. Finally, we consider air-entrained concrete (Fig. 4c) as a binary composite of impermeable aggregates embedded in a paste-void matrix. Maxwell's equation for this scenario is similar to Eq (4), but replacing $\sigma_{C}, \sigma_{P}$, and $f_{A}$ with $\sigma_{C o}, \sigma_{P o}$, and $f_{A o}$ respectively, where $\sigma_{C o}$ and $f_{A o}$ are the effective conductivity and aggregate fraction of the air-entrained concrete. We can easily rearrange the above and express the ratio $\sigma_{C o} / \sigma_{C}$ as follows. If the air voids are superconducting:

$$
\frac{\sigma_{C o}}{\sigma_{C}}=\frac{\left(\frac{1-f_{A o}}{1+0.5 f_{A o}}\right) \times\left(\frac{1+2 f_{o}}{1-f_{o}}\right)}{\left(\frac{1-f_{A}}{1+0.5 f_{A}}\right)}
$$

Or, if the air voids are non-conducting:

$$
\frac{\sigma_{C o}}{\sigma_{C}}=\frac{\left(\frac{1-f_{A o}}{1+0.5 f_{A o}}\right) \times\left(\frac{1-f_{o}}{1+0.5 f_{o}}\right)}{\left(\frac{1-f_{A}}{1+0.5 f_{A}}\right)}
$$

Figure 5 shows the estimated transport properties of the air-entrained concretes from the measured air content, aggregate fraction and transport properties of the control, using equations (5) and (6). Note that if the aggregate fractions of the control and air-entrained concrete are the same, then equations (5) and (6) reduce to (2) and (3) respectively, which are plotted in Figure 3d. For estimating diffusivity, permeability and vacuum-saturated resistivity, we assumed that the air voids are superconducting (eq. 5). For non-saturated conductivity, the air voids are insulators so Eq. (6) was used. The results show that the agreement between estimated and measured values is generally good, despite the simplicity of the modelling approach. The average errors based on absolute values ( \pm standard deviation) for diffusivity, permeability and resistivity are $18.1 \pm 15.0 \%, 17.1 \pm 17.7 \%$ and $11.8 \pm 8.8 \%$ respectively. The highest recorded error is $\sim 53 \%$.

1 2

.




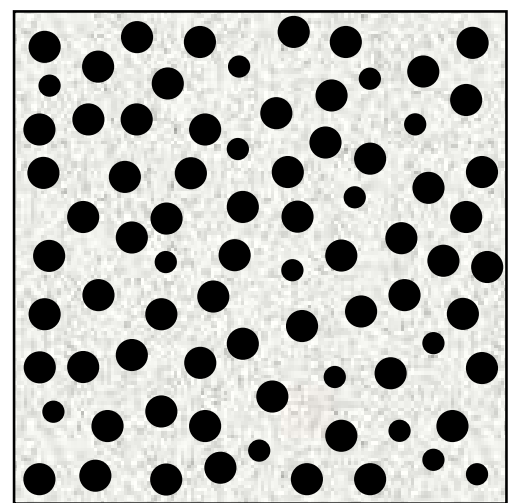

(a)

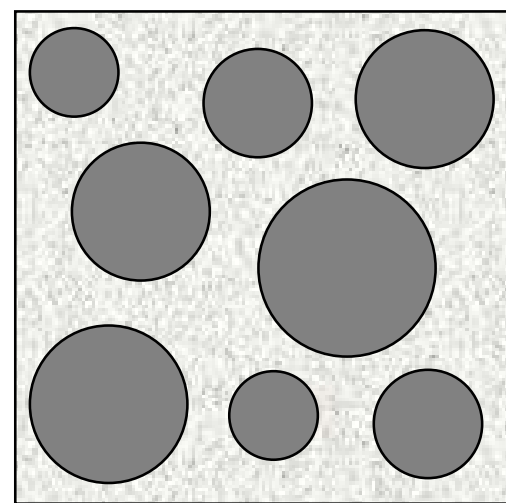

(b)

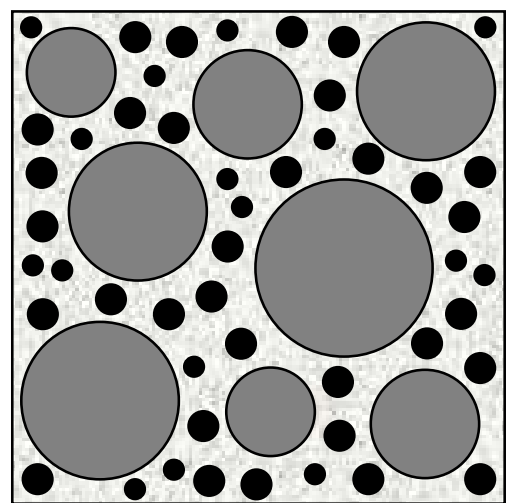

(c)

Fig. 4 Schematics showing the idealisation of air-entrained concrete to a three-phase composite consisting of spherical air voids (black) and aggregates (dark grey), embedded in a continuous paste matrix (light grey).

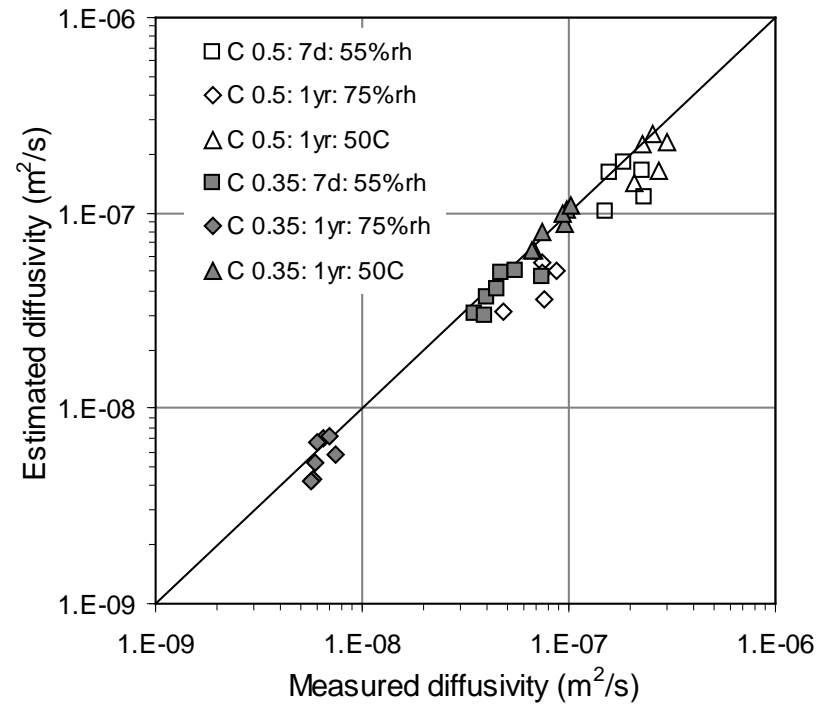

(a)

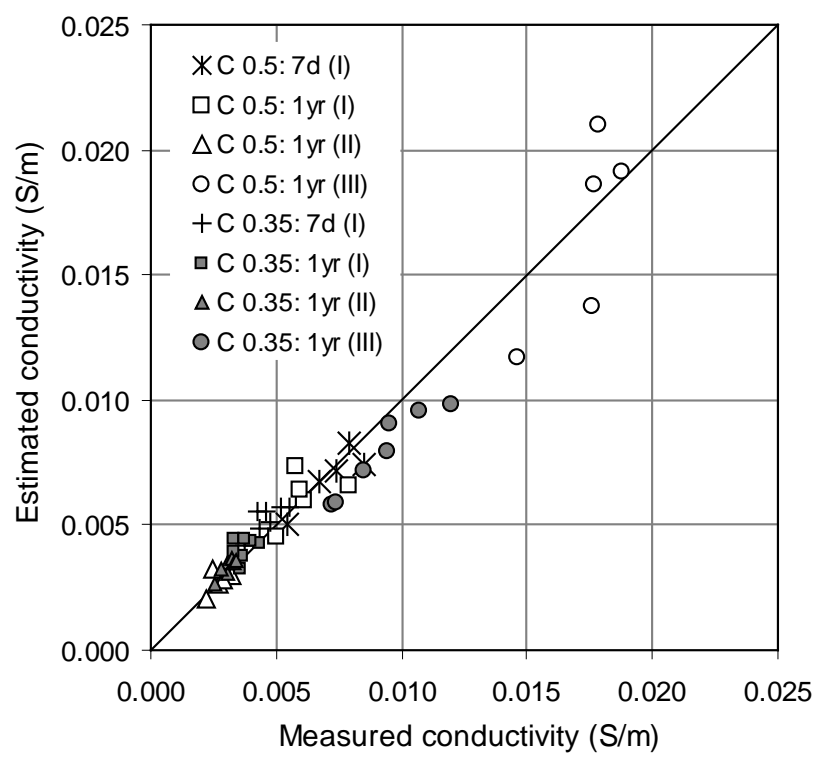

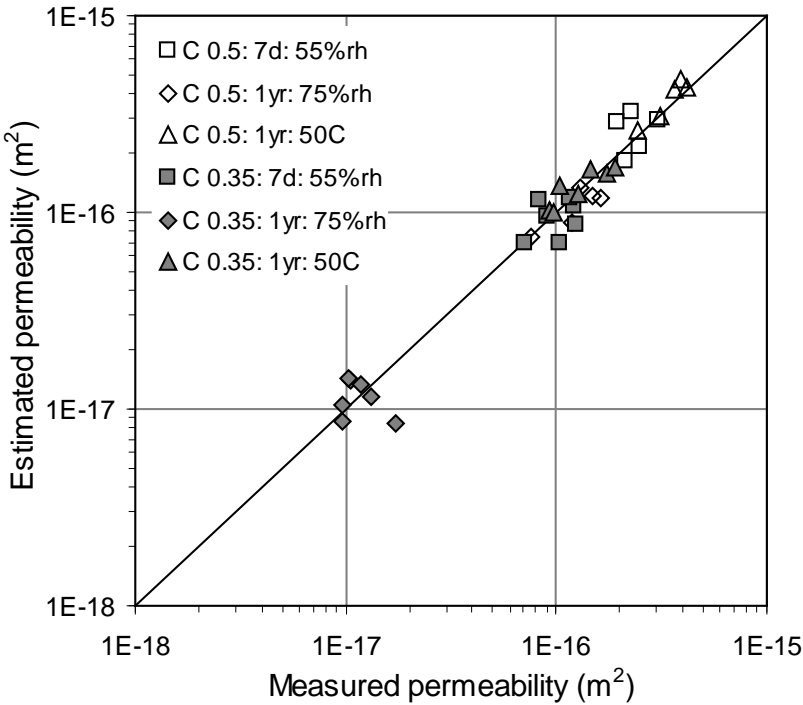

(b)

(c)

Fig. 5 Comparison between the measured and estimated transport coefficients of air-entrained concretes 


\section{Discussion}

389

390

391

392

393

394

395

396

397

398

399

400

401

402

403

404

405

406

407

408

409

410

411

412

413

414

415

416

417

418

419

420

421

422

423

424

Although entrained air voids appear to be isolated in the microstructure, they are in fact interconnected by the capillary pores that are significantly smaller in size. The entrained air voids can increase or decrease bulk transport properties, the net effect depending on the moisture state of the air voids and the transport mechanism under consideration. Our results clearly show that air voids facilitate gaseous transport. This was observed even in well-hydrated concretes with a low w/c ratio that have been conditioned at high humidity, where it would be expected that a significant portion of the capillary pores are disconnected. The increase in gaseous transport also occurred despite a decrease in total capillary porosity, such as in air-entrained samples where the aggregate fraction and w/c ratio were held constant.

However, air voids reduce the capacity for water absorption because they generate lower capillary suction compared to the capillary pores. Consequently, the air voids are filled much more slowly than are the capillaries, and they become rapidly encircled by the advancing wet front and consequently do not saturate. Since electrical conduction only occurs through ions in the pore solution, the effect of increasing the proportion of empty air voids is similar to increasing the aggregate fraction, i.e. non-conductive obstructions. The cross-section available for flow is reduced and the conduction path becomes more tortuous. Thus, electrical conductivity decreases with increasing air content. However, the trapped air may be displaced and expelled by pressure or by long-term diffusion and convection if the sample has continuous access to water [27]. Given sufficient time, the air voids may achieve saturation and this reverses the effect of air voids on electrical conductivity. These results are consistent with those of McCarter et al. [9] and Toutanji [10]. Using our simple model (eqs. 5 and 6) that is based on Maxwell's equation as an estimate, every 1\% increase in air content increases the transport coefficients by about $10 \%$ or decreases it by $4 \%$, depending on whether the voids act as conductors or insulators.

The microstructural gradients at the air void-paste interface are similar to those of the well known aggregate-paste ITZ. The gradients in porosity and unreacted cement are due to particle packing effects and suggest that the initial w/c ratio near the air voids is significantly higher than the bulk paste. However, one major difference between the microstructure of both interfaces is the lack of calcium hydroxide deposits seen at the void-paste interface, probably because less bleed water is trapped beneath air voids compared to aggregates. The width of the aggregate-cement paste 'ITZ' is related to the size of cement particles and would be expected to reduce if a finer cement or microsilica is used. The observed gradients are consistent with previous findings [28, 29], but to the best of our knowledge, the microstructure of the air void-paste transition zone has never been quantitatively characterised. Rashed \& Williamson [28] examined the microstructure of freeze-dried and fractured surfaces of air-entrained concretes at early ages. They observed a thin shell $(\sim 1-2 \mu \mathrm{m})$ of hydration products at the air voids and a transition zone between the shell and bulk paste that is about 10$15 \mu \mathrm{m}$ wide. Using low temperature SEM, Corr et al. [29] also observed distinctive air void shells and presence of porous transition zones between the shell and bulk paste. However, these authors noted that the transition zone might have been formed by shrinkage of the air void due to liquid nitrogen quenching.

In the modelling work, we have assumed that the air voids and aggregates do not influence hydration kinetics, and that the properties of the paste matrix in the control and air-entrained concrete are identical. The latter is not strictly true, since the air voids disturb the paste microstructure, as discussed above. However, a higher porosity near the interface is 
balanced by lower bulk porosity, due to water conservation, so we have ignored any variation at the micro-scale and considered only the averaged macroscopic behaviour, which is taken to be invariant to aggregate or air content. Aggregates may release some absorbed water and promote hydration, although this effect is trivial for dense aggregates. The air voids may influence hydration kinetics, but we note that the 1-year old samples tested in this study were continuously cured in a fog room, so this effect would not be substantial.

The air void-paste interface occupies a significant fraction of the cement paste (Fig. 2c) and it is expected to have a major influence on bulk behaviour. A question that arises is whether the higher transport property of air-entrained concretes is primarily due to the overlapping and interconnection of the porous interface, rather than due to the air voids per se. Comparing the electrical conductivity under saturated and non-saturated conditions in Fig. 3d suggests that this is not the case and that transport thru air voids is indeed important. Moreover, our recent work on the aggregate-paste ITZ show that the net effect of the ITZ on bulk transport properties is small, despite its higher porosity and transport coefficients [30, 31]. This trend was consistent across many variables including binder type, w/c ratio, curing age, different transport mechanisms, and even after a severe drying treatment to induce microcracking.

It should be noted that the spacing of the air voids at a given air content depends on the size distribution of the voids, and so can be quite variable. For example, Saucier et al. [32] found that the spacing factor can range between 100 and $400 \mu \mathrm{m}$ at an air content of $6 \%$. Thus, one should aim to produce concretes with a closely spaced air void system at the lowest air content, to reduce the detrimental effect of entrained air on strength. It would also be interesting to examine the influence of spacing factor on transport properties independent of the air content. Another aspect that we have not considered is the effect of air voids on shrinkage-induced microcracking that may occur due to drying prior to transport testing. Microcracking is expected to initiate at the numerous porous interfaces, increase connectivity and accentuate any effects of air voids on transport. This merits further investigation. Further work on the effect of entrained air on chloride and carbonation induced corrosion of reinforcement in concrete is currently ongoing.

\section{Conclusions}

The microstructure and mass transport properties of concretes with up to $11.5 \%$ volume of entrained air and at different w/c ratios (0.35 and 0.50), curing ages (7 and 365 days) and conditioning regimes (52\% r.h., $75 \%$ r.h. and $50^{\circ} \mathrm{C}$ oven drying) were investigated. The evidence shows that the microstructure of the air void-paste interface is similar to that of the aggregate-paste interfacial transition zone, in that it contains significantly lower cement content, higher porosity, and higher initial w/c ratio compared to 'bulk paste' farther away from the interface. Air voids disrupt the packing of cement grains and increase the heterogeneity of the paste microstructure. The porosity near the air void boundary is about 2-3 times that of the bulk paste, and the width of the interface is around $30 \mu \mathrm{m}$ from the void boundary. However, no significant precipitation of calcium hydroxide was observed at the air void-paste interface. Entrained air voids can increase or decrease transport properties, depending on the transport mechanism under consideration, and the moisture content of the voids. Air entrainment increases gaseous diffusivity and permeability by up to a factor of 2-3 at the highest air contents, regardless of the w/c ratio, curing age and conditioning regime. The effect of air entrainment is similar to increasing w/c ratio from 0.35 to 0.50 when samples are dried to remove most of the moisture in the capillary pores. The effect on sorptivity is less consistent, although a greater number of data points showed a decreasing rather 
than an increasing trend. Under non-saturated conditions, empty air voids act as insulators and the bulk electrical conductivity is decreased. However, saturated air voids behave as conductors and increase electrical conductivity. Using our simple model (eqs. 5 and 6) that is based on Maxwell's equation it is estimated that every 1\% increase in air content increases the transport coefficient by about $10 \%$ or decreases it by $4 \%$, depending on whether the air voids act as conductors or insulators. Good agreement was observed between the estimated and measured transport coefficients, which span up to two orders of magnitude in the case of gas diffusion and gas permeation.

\section{Acknowledgements}

We thank Mr. Andrew Morris for his help with the laboratory work. This study was carried out with financial support from the Engineering and Physical Sciences Research Council (EPSRC) through grant EP/F002955/1, which we gratefully acknowledge.

\section{References}

1. T.C. Powers (1949), Air requirement of frost-resistant concrete, Proceedings, Highway Research Board, 29, 184-211

2. M. Pigeon, R. Pleau (1995), Durability of Concrete in Cold Climates, E \& FN Spon, 244p

3. ACI 201.2R-01, Guide to durable concrete, ACI Manual of Concrete Practice, 2005

4. ACI 212.3R-01, Chemical admixtures for concrete, ACI Manual of Concrete Practice, 2005

5. K.C. Hover (2006), Air content and density of hardened concrete, In: Significance of Tests and Properties of Concrete and Concrete Making Materials, P. Klieger \& J.F. Lamond (eds), ASTM STP 169C, 296-319

6. P.F. Gutmann (1988), Bubble characteristics as they pertain to compressive strength and freeze-thaw durability, ACI Mat. J., 85, 361-366.

7. K.C. Hover (1989), Some recent problems with air entrained concrete, Cem. Concr. Aggreg., 11 [1] 67-72

8. J.M. Aldred (1987), The relative importance of permeability and sorptivity in the durability of reinforced concrete, Fourth International Conference on Durability of Building Materials and Components, Singapore, 752-761.

9. W.J. McCarter, M. Forde, H.W. Whittington T. Simons (1983), Electrical resistivity characteristics of air-entrained concrete, Proc. Instn. Civ. Engrs., Pt. 2, 75, 123-127

10. H.A. Toutanji (1998), The influence of air entrainment on the properties of silica fume concrete, Adv. Cem. Res., 10 [3] 135-139

11. AASHTO T227-93 (1983), Electrical indication of concrete's ability to resist chloride, American Association of State Highway and Transportation Officials, Washington.

12. H.S. Wong, N.R. Buenfeld (2006), Patch microstructure in cement-based materials: Fact or artefact? Cem. Concr. Res., 36 [5] 990-997.

13. ASTM C457-09, Standard test method for microscopical determination of parameters of the air-void system in hardened concrete, ASTM Book of Standards, Vol. 04.02. 
14. H.S. Wong, N.R. Buenfeld (2006), Euclidean Distance Mapping for computing microstructural gradients at interfaces in composite materials, Cem. Concr. Res., 36 [6] 1091-1097.

15. H.S. Wong, M.K. Head, N.R. Buenfeld (2006), Pore segmentation of cement-based materials from backscattered electron images, Cem. Concr. Res., 36 [6] 1083-1090.

16. M.K. Head, H.S. Wong, N.R. Buenfeld (2008), Characterising aggregate surface geometry in thin sections of mortar and concrete, Cem. Concr. Res., 38, 1227-1231.

17. N.R. Buenfeld, E. Okundi (1998), Effect of cement content on transport in concrete, Mag. Concr. Res., 50 [4] $339-$ 351.

18. H.S. Wong, N.R. Buenfeld, J. Hill, A.W. Harris (2007), Mass transport properties of mature wasteform grouts, Adv. Cem. Res., 18 [1] 1-12.

19. M.P. Lutz, P.J.M. Monteiro, R.W. Zimmerman (1997), Inhomogeneous interfacial transition zone model for the bulk modulus of mortar, Cem. Concr. Res., 27 [7], 1113-1122.

20. R. Landauer (1978), Electrical conductivity in inhomogeneous media, AIP Conf. Proc. No. 40, Electrical Transport and Optical Properties of Inhomogeneous Media, J.C. Garland and D.B. Tanner (eds.), American Institute of Physics, New York, 2-45.

21. D.S. McLachlan, M. Blaszkiewicz, R.E. Newnham (1990), Electrical resistivity of composites, J. Amer. Ceram. Soc., 73 [8] 2187-2203.

22. T.C. Choy (1999), Effective medium theory: Principles and applications, Oxford University Press.

23. S. Torquato (2002), Random heterogeneous materials: Microstructure and macroscopic properties, Springer, New York.

24. Z. Hashin, S. Shtrikman (1962), A variational approach to the theory of the effective magnetic permeability of multiphase materials, J. Appl. Phys., 33, 3125-3131.

25. H.W. Whittington, J. McCarter, M.C. Forde (1981), The conduction of electricity through concrete, Mag. Concr. Res., 33, 48-60.

26. R. W. Zimmerman (1989), Thermal conductivity of fluid-saturated rocks, J. Petrol. Sci. Eng., 3, 219-227.

27. C. Hall, W.D. Hoff (2002), Water transport in brick, stone and concrete, Taylor \& Francis, London, 336p.

28. A.I. Rashed, R.B. Williamson (1991), Microstructure of entrained air voids in concrete, Part I, J. Mater. Res., 6 [9] 2004-2012.

29. D.J. Corr, J. Lebourgeois, P.J.M. Monteiro, S.J. Bastacky, E.M. Gartner (2002), Air void morphology in fresh cement paste, Cem. Concr. Res., 32, 1025-1031.

30. H.S. Wong, M. Zobel, N.R. Buenfeld, R.W. Zimmerman (2009), Influence of the interfacial transition zone and microcracking on the diffusivity, permeability and sorptivity of cement-based materials after drying, Mag. Concr. Res., 8, 571-589.

31. J.J Zheng, H.S. Wong, N.R. Buenfeld (2009), Assessing the influence of ITZ on the steady-state chloride diffusivity of concrete using a numerical model, Cem. Concr. Res. 39, 805-813. 
535 32. F. Saucier, M. Pigeon, G. Cameron (1991), Air void stability, Part V: Temperature, general analysis and 536 performance index, ACI Mater. J., 88, 25-36. 